\title{
Detection of Seismo-ionospheric Anomalies using Wavelet based techniques
}

\author{
${ }^{1}$ Anjana Sonakia, ${ }^{2}$ D.K. Sondhiya, ${ }^{3}$ S.K. Kasde, ${ }^{4}$ Harsha Jalori and ${ }^{5}$ A.K. Gwal \\ ${ }^{1,2,3,5}$ Department of Physics, Barkatullah University, Bhopal-462026, India \\ ${ }^{4}$ Institute for Excellence in Higher Education, Bhopal-462021, India
}

\begin{abstract}
A number of papers have reported on anomalous variation in ionospheric foF 2 parameter and/or ionospheric total electron content (ITEC) in the vicinity of earthquake's epicenter few days prior to the earthquake. In this work empirical dependency for the seismo-ionospheric disturbances relating the earthquake magnitude and the epicenter distance are obtained. They have been shown to be similar to those obtained earlier earthquakes. The dependences indicate the process of spreading the disturbance from the epicenter towards periphery during the earthquake preparation process. Large lead times for the precursor occurrence (up to 34 days for $M=5.8-5.9$ ) tells about a prolong preparation period. It is shown that different analyses of observed foF 2 values lead to different conclusions regarding possible ionospheric precursors. Here we analyze the foF 2 and ITEC observations over Greece prior to the three very large earthquakes of January 08, 2006, February 14, 2008 and June 08, 2008, using the wavelet based techniques.
\end{abstract}

Keywords: Wavelet Transform, ionospheric anomalies and foF 2 parameter

\section{Introduction}

Earthquake is still an unpredictable natural disaster up to now, although there have been increasing interests in studying the ionospheric anomalies prior to earthquakes during the last three decades. Observation of ionospheric anomalies related to earthquake by ground-based equipment is a beneficial attempt to explore the impending earthquake prediction. The book of Ionospheric Precursors of Earthquakes, written by Pulinets and Boyarchuk [1], summarizes a large number obvious disturbance of the critical frequency observed by the ground-based ionospheric vertical sounding a few days before the quake.

Scientists observed anomalies appearing in electron densities of the ionospheric F-region few days before the strong earthquakes [2-3]. Liu et al. examined the ionospheric plasma frequency (or electron density) recorded by a local ionosonde and found that the critical frequency of the F2-peak (foF2), significantly decreased few days prior to $M \geq 6.0$ earthquakes in the Taiwan area between $1994-1999$ [3]. Ionosondes have been the most popular instrument probing the ionospheric electron density for more than seven decades [4]. Many results show anomalous behavior of ionospheric foF2 parameter few days before earthquake [5-12]. Xu et al. briefly present the observations of the giant perturbations in the ionosphere foF2 parameter prior to the Wenchuan earthquake and introduce the network of ground-based high-resolution ionospheric observation (GBHIO), using vertical and oblique ionosondes for monitoring seismo-ionospheric anomaly [13].

The goal of this work is not to explain the possible connection between ionospheric anomalies and earthquakes, since this is still under debate in the scientific community. Our first goal is to demonstrate the variation of ionospheric foF2 parameter and Ionospheric Total Electron Content (ITEC) during earthquake occurred at Greece. Secondly, we shows some new results from the unpublished data and increase the reliability of the results of the farfield sites in the previous studies using Wavelet based techniques. The result shows some unusual perturbations foF2 and ITEC some days before the main shock. This anomalous behavior of perturbations may be used as earthquake precursor.

\section{Wavelet Analysis}

General overview of Wavelet analysis may be found in [14-16]. Wavelet analysis uses a time localized oscillatory function as the Mother Wavelet. Using the Mother Wavelet function $\Psi(t)$ the continuous wavelet transform of ionosphric parameter $f(t)$ is defined as:-

$$
(w f)(a, b)=\frac{1}{\sqrt{a}} \int_{-\infty}^{\infty} f(t) \bar{\psi}\left(\frac{t-b}{a}\right) d t
$$

Where,

$a=$ dilation parameter

$b=$ translation parameter 


$$
\bar{\psi}=\text { complex conjugate of } \Psi(t)
$$

To ensure the existence of inverse wavelet transform mother wavelet satisfy the condition of admissibility given by-

$$
C_{\psi}=\int_{-\infty}^{\infty} \frac{\left|F_{\psi}(\omega)\right|^{2}}{|\omega|} d \omega<\omega
$$

Where $F_{\psi}(\omega)=$ Fourier transform of $\Psi(t)$

The signal $f(t)$ may be synthesized or reconstructed by an inverse wavelet transform of $(w f)(a, b)$ as defined by

$$
f(t)=\frac{1}{C_{\psi}} \int_{-\infty-\infty}^{\infty} \int_{-\infty}^{\infty}(w f)(a, b) \psi\left(\frac{t-b}{a}\right) \frac{1}{a^{2}} d a d b
$$

In practice discrete wavelet transform is used in which the dilation parameter $a$ and the translation parameter $b$ are discrete. These procedures become much more efficient, if dyadic values of parameters $a$ and $b$ are used.

Where $Z=$ set of positive integer

$$
a=2^{j}, b=2^{j} k j, k \in Z
$$

For a special cases of $\Psi(t)$, corresponding discretized wavelets $\psi_{j k}(t)$ is used, which is given by

$$
\psi_{j k}(t)=2^{\frac{j}{2}} \psi\left(2^{j} t-k\right)
$$

Which constitute an orthogonal basis for $L^{2}(R)$ [15], [17-18]

In discrete wavelet transform a signal can be represented by its approximations and details. The details at level $j$ are defined as:

and approximation at this level

$$
D_{j}=\sum_{k \in Z} a_{j k} \psi_{j k}(t)
$$

$$
A_{j}=\sum_{j=J} D_{j}
$$

Its become obvious that

$$
\begin{gathered}
A_{j}-1=A_{j}+D_{j} \\
\text { And } f(t)=A_{j}+\sum_{j \leq J} D_{j}
\end{gathered}
$$

These equations provide a tree structure of a signal and also a reconstruction process for the signal.

\section{Data Selection}

In this study data of ionospheric foF2 parameter and ionospheric total electron content (ITEC) were taken from NOAA's National Geophysical Data Center (NGDC) available online at www.ngdc.noaa.gov. For the proper selection of Ionosnde station famous Dobrovolsky equation was used in this work. Analytically written as [19]:

$$
\rho=10^{0.43 M} \mathrm{~km}
$$

Where $\rho$ is the radius of the earthquake preparation zone and $M$ is the magnitude. The validity of the Dobrovolsky's formula for estimating the size of a modified area in the ionosphere before earthquakes used [20] and [21].

We have select three earthquakes near Athens ionosnde station for the study.The characteristics of these earthquakes were summarized in Table -1 . 
Table-1

Characteristics of Earthquakes

\begin{tabular}{|c|c|c|c|c|c|c|c|c|}
\hline SN & Earthquake & Date & Epicenter & Time & $\mathbf{M}$ & $\begin{array}{c}\text { Depth } \\
(\mathbf{k m})\end{array}$ & $\begin{array}{l}\text { Name of nearest } \\
\text { Ionosonde station }\end{array}$ & $\begin{array}{l}\text { Distance between } \\
\text { epicenter and } \\
\text { Ionosonde station }\end{array}$ \\
\hline 1 & $\begin{array}{l}\text { Greece- } \\
\text { southern }\end{array}$ & 08/01/2006 & $36.30^{\circ} \mathrm{N}, 23.36^{\circ} \mathrm{E}$ & $11: 34: 55$ & 6.8 & 66 & $\begin{array}{c}\text { Athens } \\
38^{\circ} \mathrm{N}, 24^{\circ} \mathrm{E}\end{array}$ & $197 \mathrm{~km}$ \\
\hline 2 & $\begin{array}{l}\text { Greece- } \\
\text { southern }\end{array}$ & $14 / 02 / 2008$ & $36.64^{\circ} \mathrm{N}, 21.83^{\circ} \mathrm{E}$ & 10:09:23 & 6.9 & 29 & $\begin{array}{c}\text { Athens } \\
38^{\circ} \mathrm{N}, 24^{\circ} \mathrm{E}\end{array}$ & $200 \mathrm{~km}$ \\
\hline 3 & $\begin{array}{c}\text { Greece- } \\
\text { peloponnese }\end{array}$ & 08/06/2008 & $38.02^{\circ} \mathrm{N}, 21.46^{\circ} \mathrm{E}$ & $13: 25: 00$ & 6.4 & 16 & $\begin{array}{c}\text { Athens } \\
38^{\circ} \mathrm{N}, 24^{\circ} \mathrm{E}\end{array}$ & $222 \mathrm{~km}$ \\
\hline
\end{tabular}

In order to classify the effect of geomagnetic activity on considered parameter during the earthquake geomagnetic Dst index should be checked. It is collected from WDC Kyoto, Japan and OMINI web data server. According to international classification the geomagnetic disturbance classified as a magnetic storm if the Dst index exceeds the value of $-51 \mathrm{nT}$ [22]. The variation of Dst index for the month of January 2006, February 2008 and May 2008 are shown in Fig. 1. It was noticed that for all earthquake Dst values were below the threshold level.

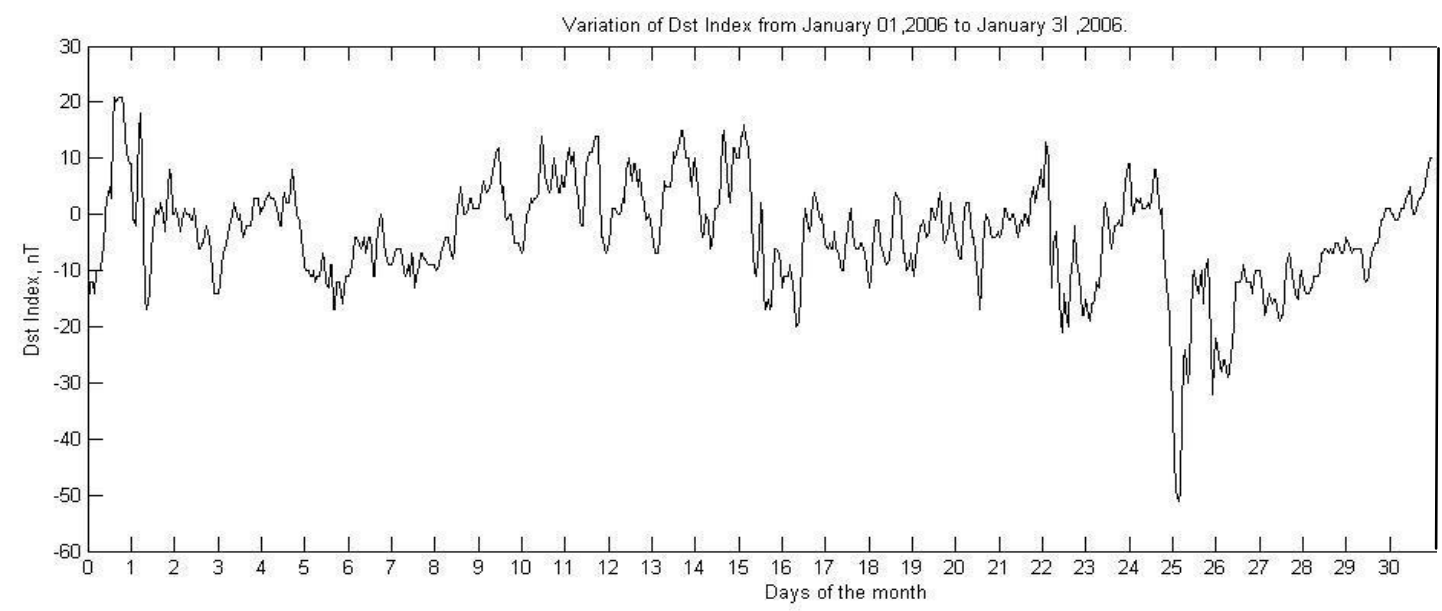

(a)

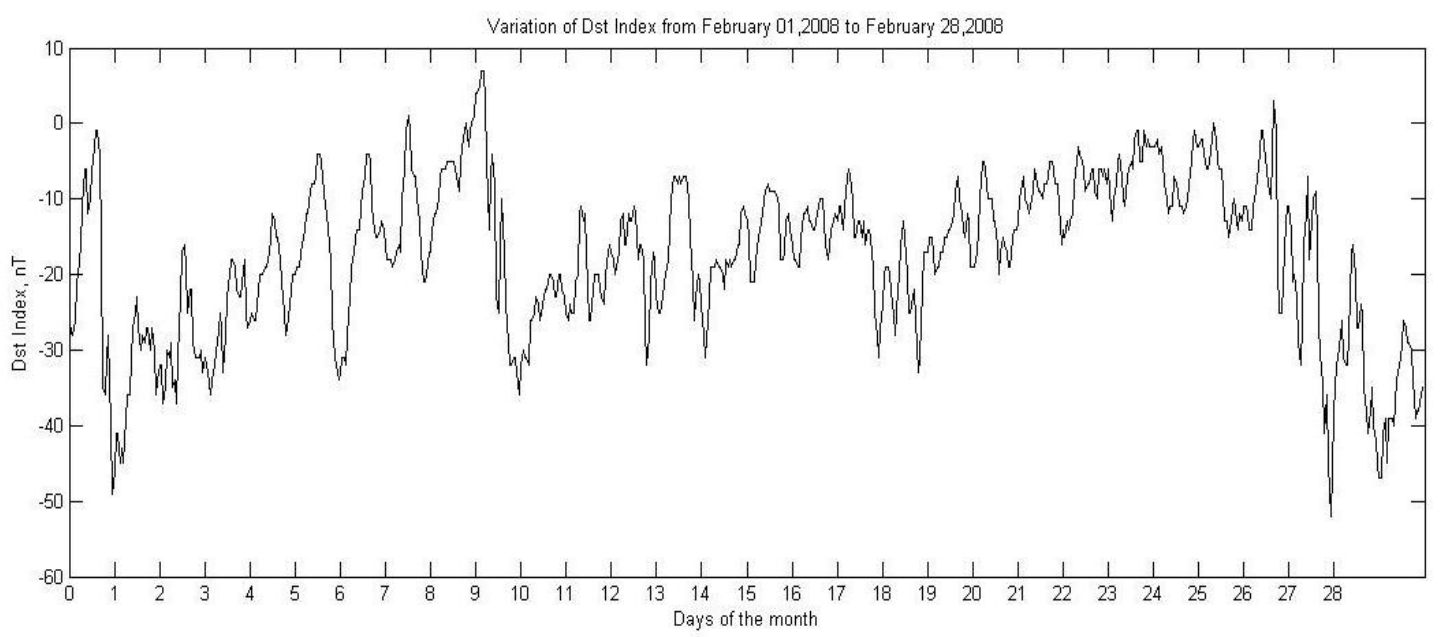

(b) 


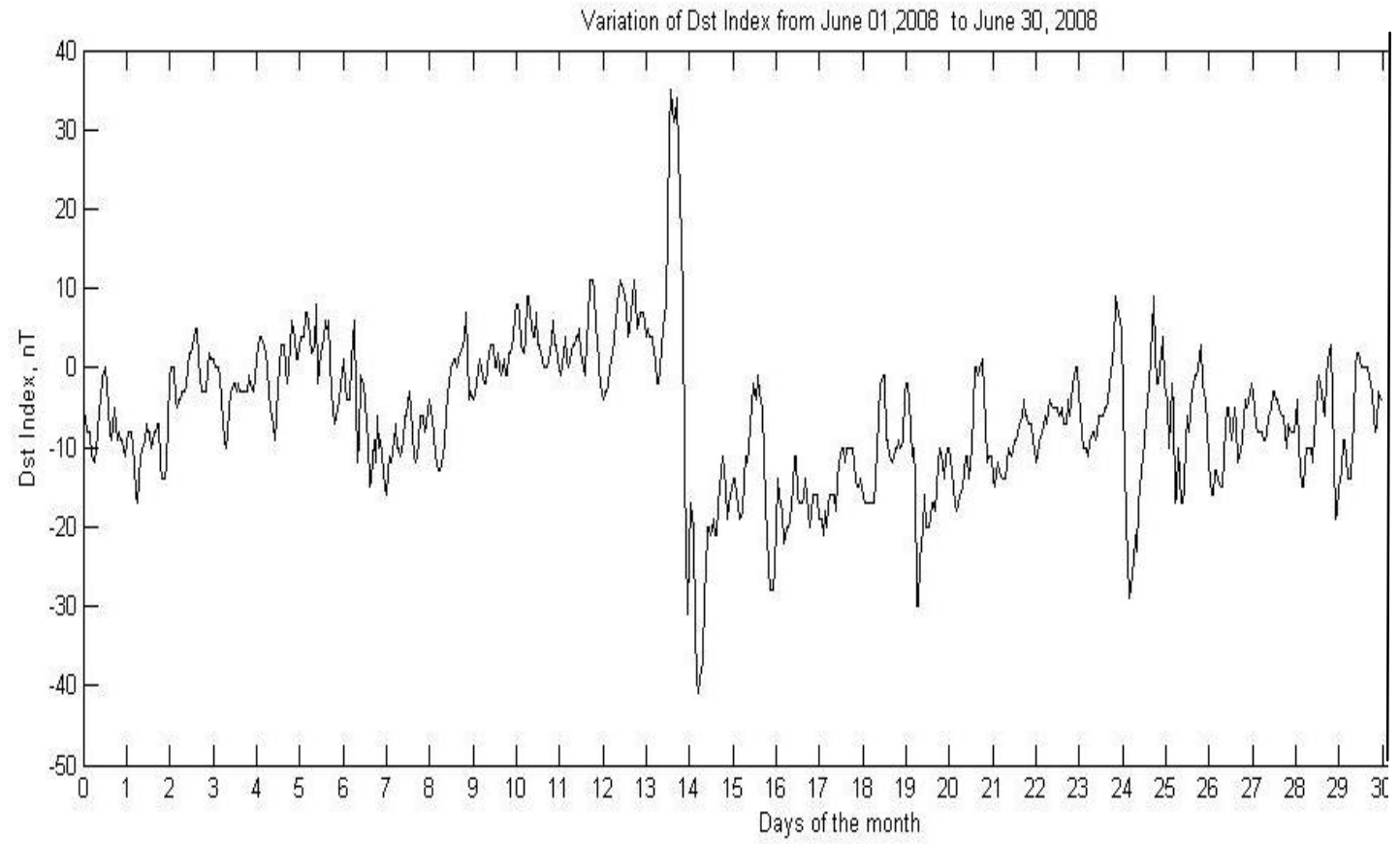

(c)

Fig. 1 Daily variation geomagnetic Dst Index for the moth (a) January, 2006 (b) February, 2008 and (c) June, 2008

\section{Case Study And Results}

Analysis of ionospheric parameters revealed some anomalous common feature of ionospheric variability few days before main shock. These anomalies are expressed in terms of variation in ionospheric foF 2 parameter and Ionospheric Total Electron Content (ITEC). We present three cases of earthquakes in which ionospheric perturbations were observed. Results related to these earthquakes are described below.

\subsection{Greece - Southern Greece Earthquake occurred on January 08, 2006}

The earthquake discussed took place on January 9, 2006, at 1:34 pm local time in Southern Greece $\left(36.30^{\circ} \mathrm{N}, 23.36^{\circ} \mathrm{E}\right)$. Its depth was $66 \mathrm{~km}$ and the magnitude was $\mathrm{M}=6.8$. Variation in foF2 (upper panel) parameter and ITEC (lower panel) was illustrated in Fig. 2. Discrete Wavelet Transform (DWT) of foF2 parameter and ITEC were given in Fig. 3 (a) and Fig. 3 (b) respectively. In figure upper panel shows the variation in parameter middle and lower panel shows the variation in wavelet detail coefficient and values of selected wavelet coefficient on 2D graph. It gives abrupt change in ionospheric parameter six day (i.e. January 04, 2006) before the earthquake. The Continuous Wavelet Transform (CWT) displays the scale-dependent structure, so that the CWT provides a view of the frequency versus time behavior of the signal and therefore has great potential as a preliminary tool for investigating wideband, non-stationary or other types of signals having time-dependent spectral characteristics. Fig. 4 (a) and 4 (b) shows the step by step mode of continuous wavelet 1-D of foF2 and ITEC parameter. It is found that both parameters exhibit highly non-stationary nature before the earthquake. 
Variation offo:2

[Eathwyake occured on January 08, 2006]

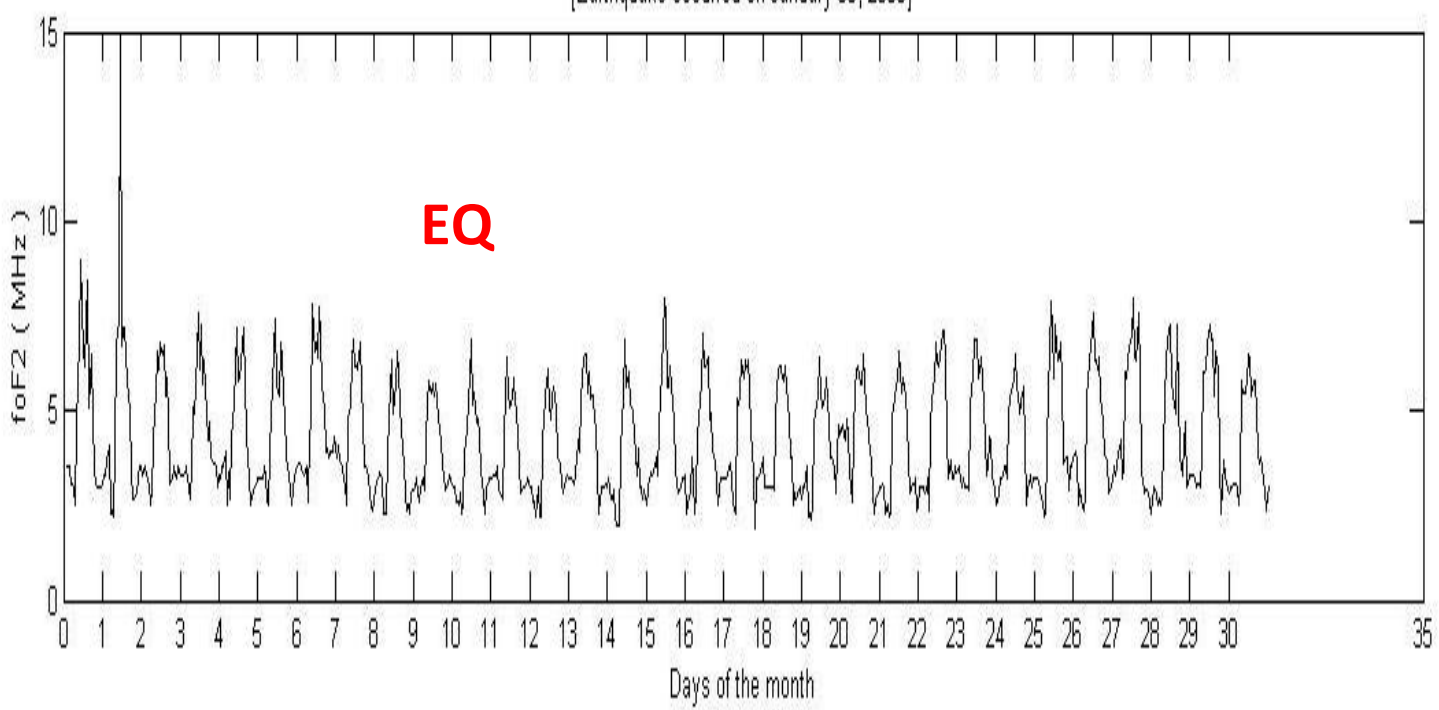

Variation of TEC

[Eath huake occured on January 08, 2006]

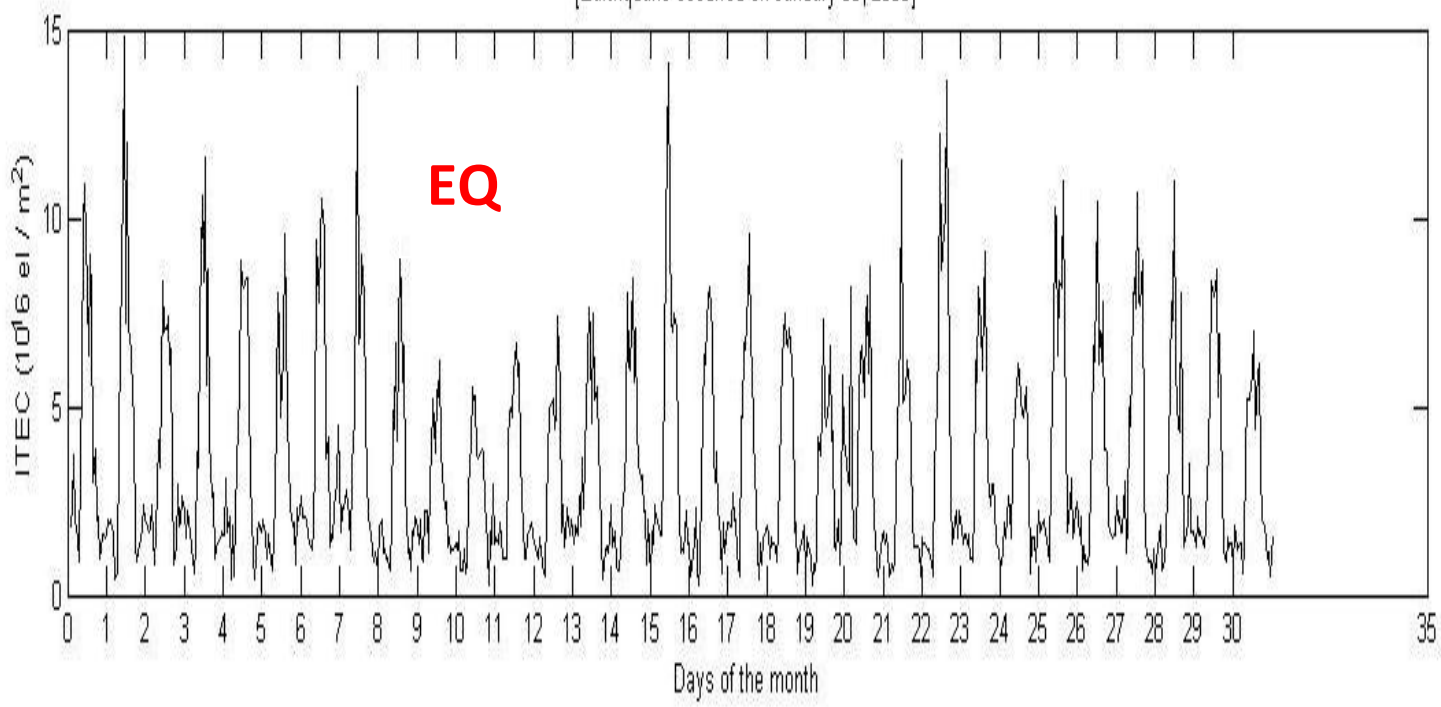

Fig. 2 Variation of ionospheric foF2 parameter and ionospheric Total Electron Content (ITEC) during Southern Greece Earthquake occurred on January 08, 2006 
Signal and Approximation at level 1

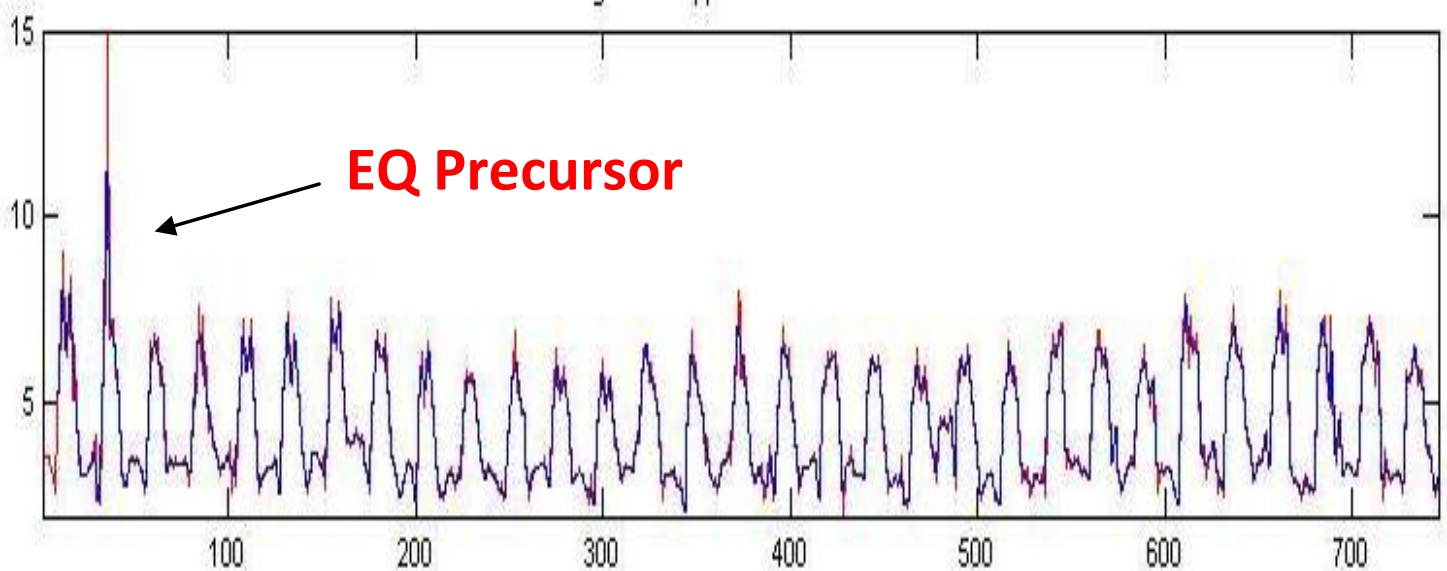

Detail at level 1

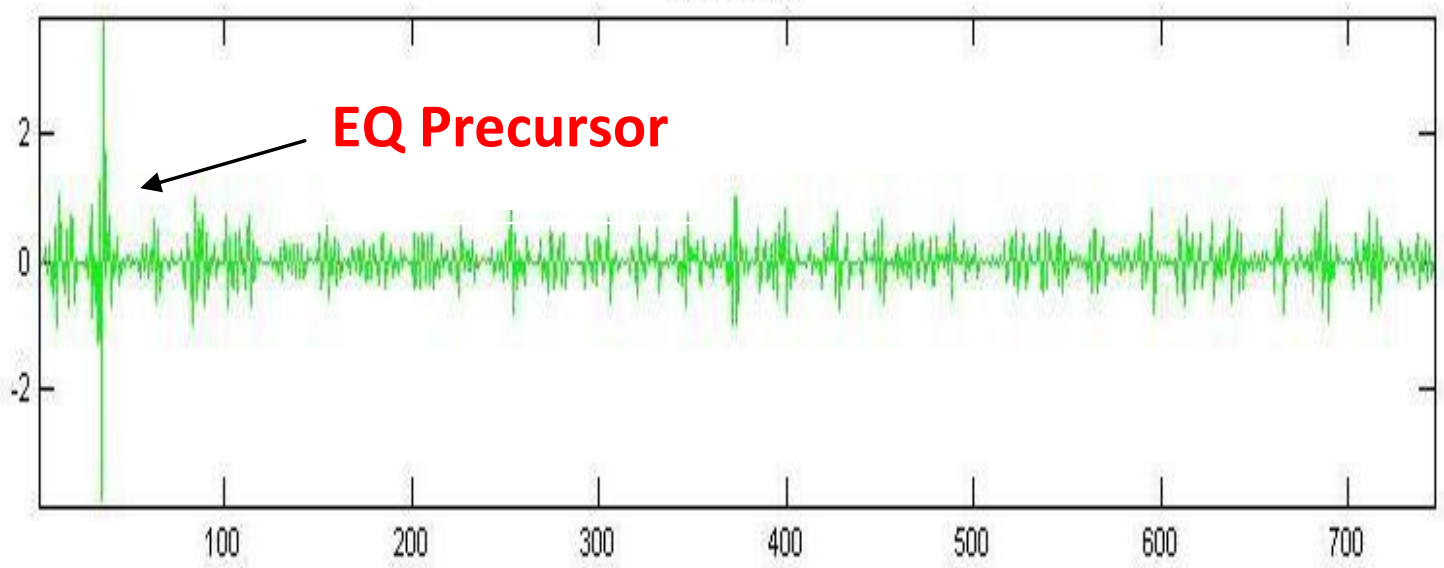

Detalls Coefficierts

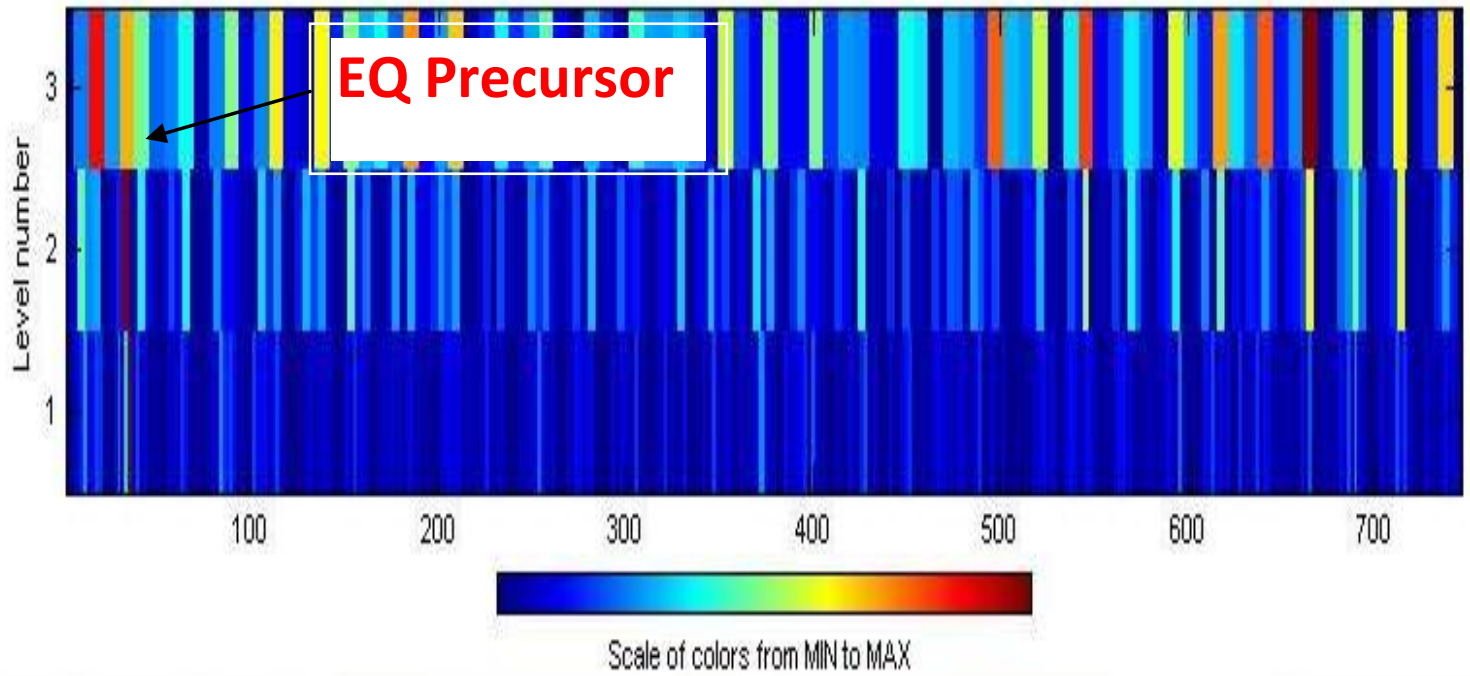

Fig. 3 (a) Discrete Wavelet Transform of Ionospheric foF2 parameter during Southern Greece Earthquake occurred on January 08, 2006 
Signal and Approximation at level 1

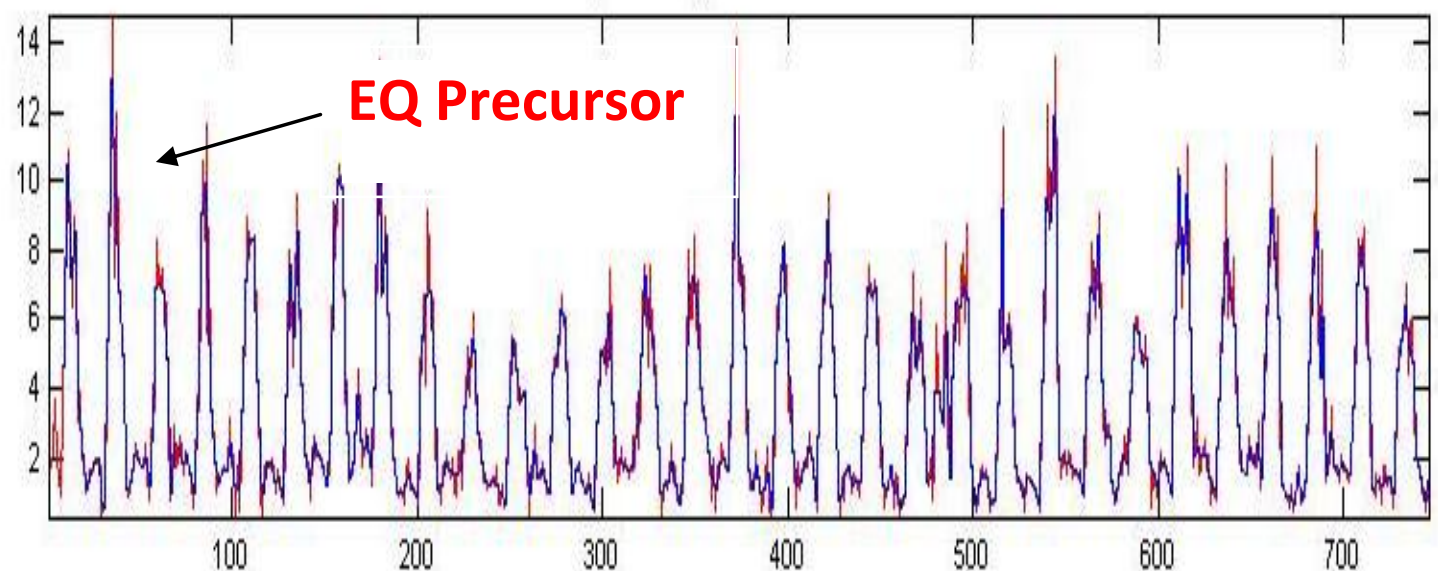

Detail at level 1

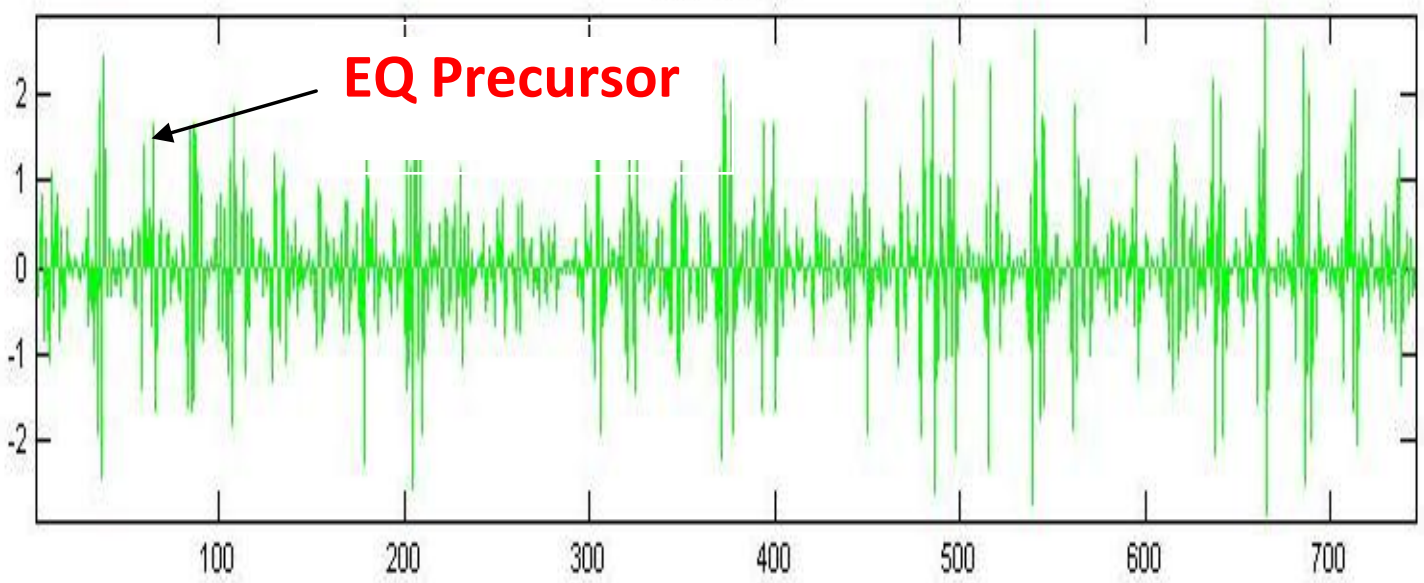

Detalls Coefficierts

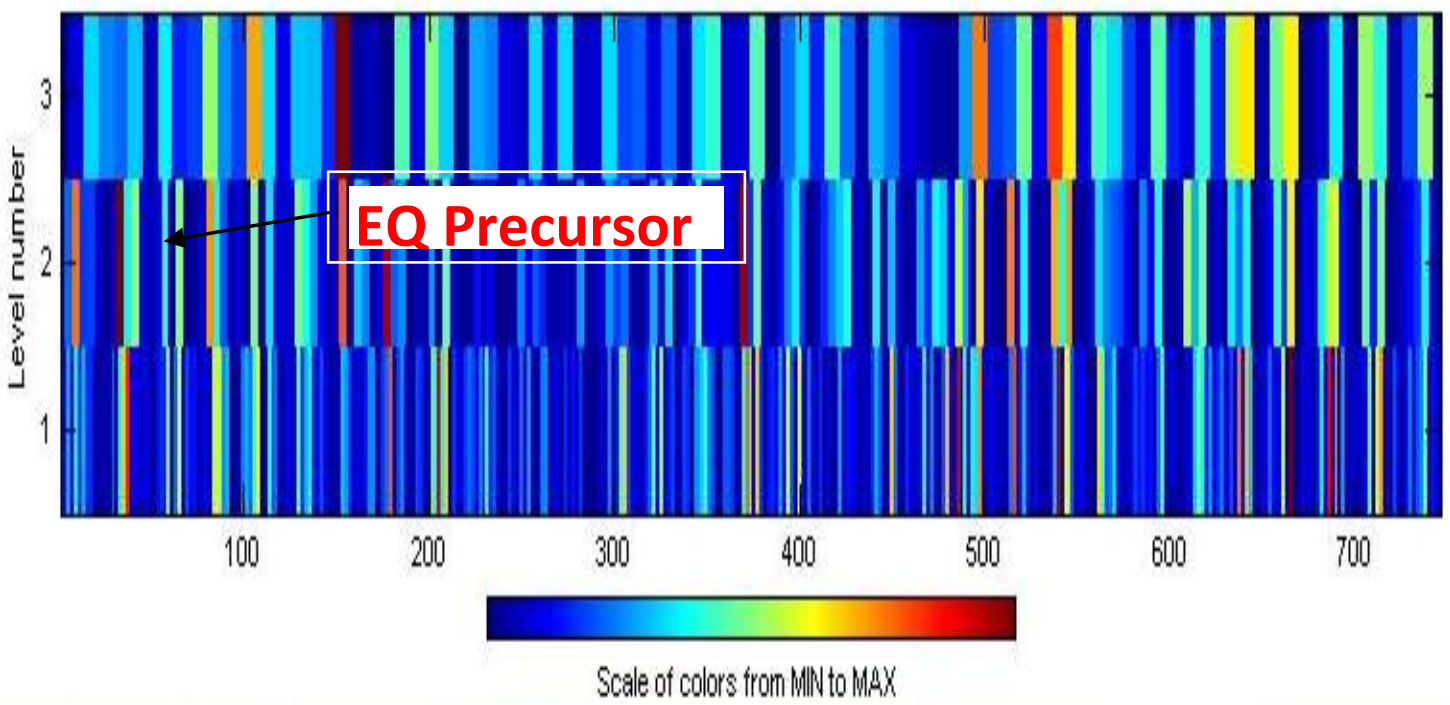

Fig. 3 (b) Discrete Wavelet Transform of Ionospheric Total Electron Content (ITEC) during Southern Greece Earthquake occurred on January 08, 2006 

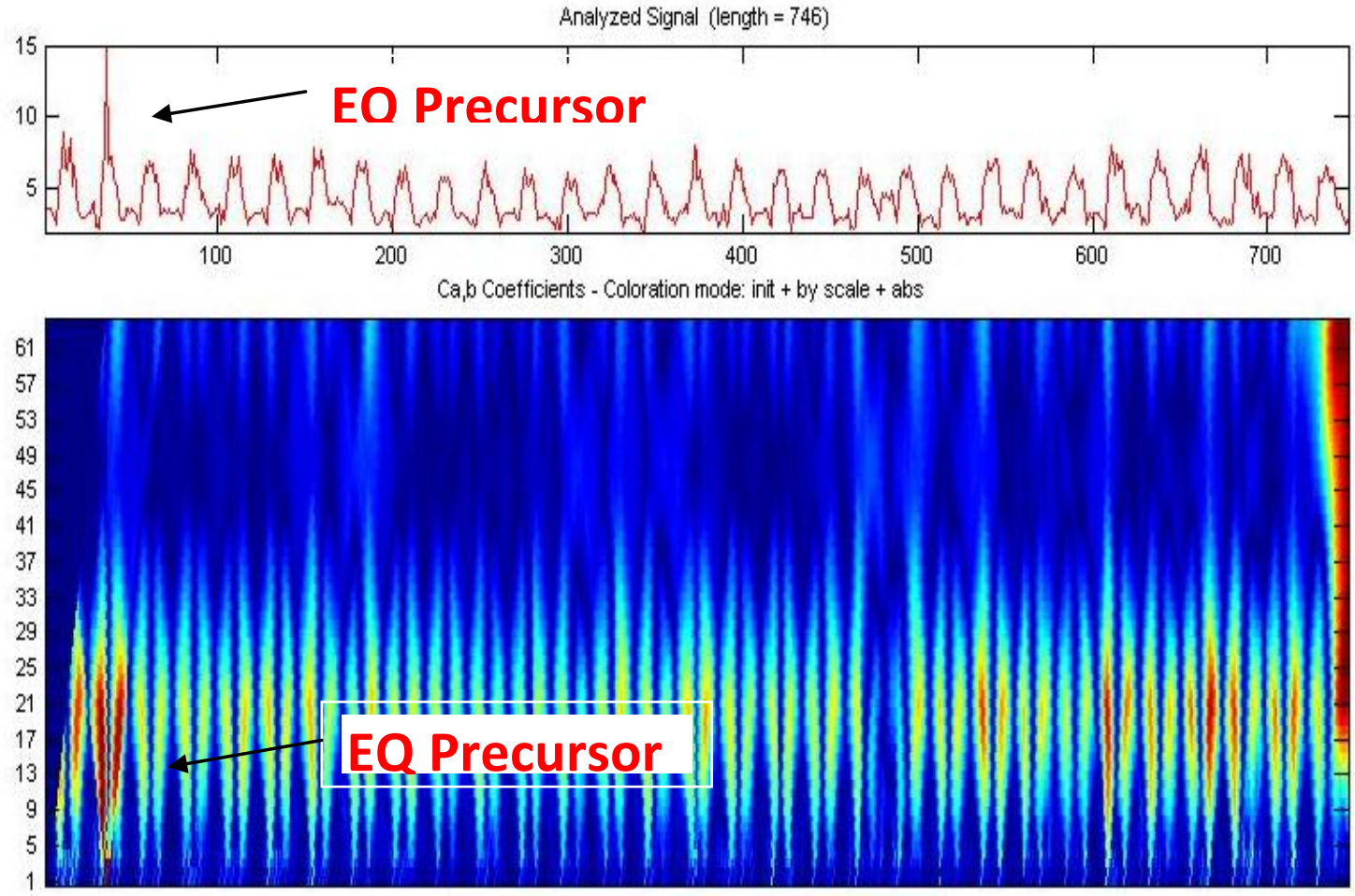

Scale of colors from MIN to MAX

Fig. 4 (a) Continuous wavelet transform of Ionospheric foF2 parameter during Southern Greece Earthquake occurred on January 08, 2006

Analyzed Signal (length $=746$ )
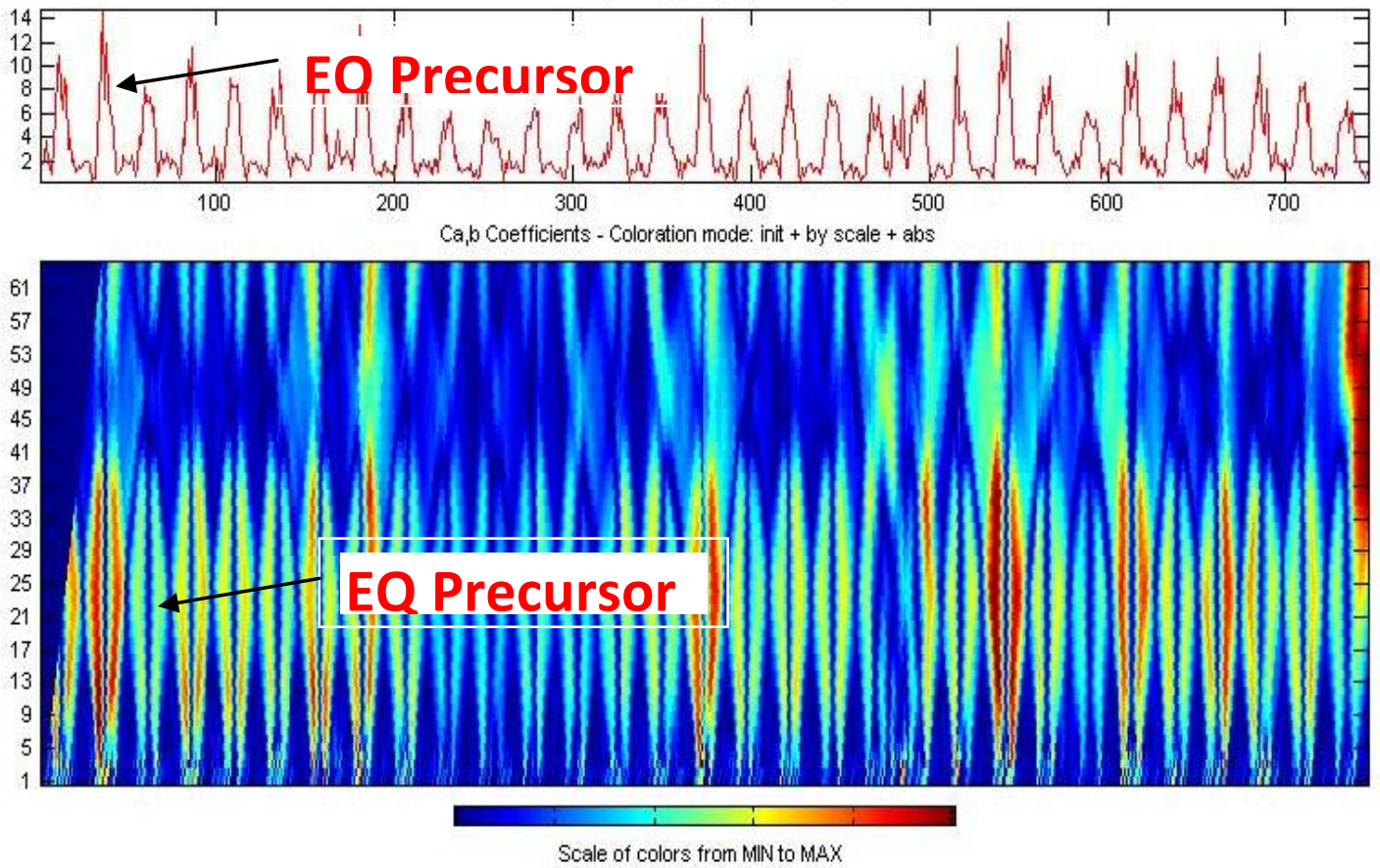

Fig. 4 (b) Continuous wavelet transform of ionospheric Total Electron Content (ITEC) during Southern Greece Earthquake occurred on January 08, 2006

1.2 Greece-Southern Earthquake occurred on February 14, 2008

Strong and dangerous earthquake with recorded magnitude of 6.9 struck Southern Greece $\left(36.646^{\circ} \mathrm{N}\right.$, $21.833^{\circ} \mathrm{E}$ ) on February 14, 2008 at 10:09:23 UTC. It was depth $29 \mathrm{~km}$. Anomalous variation in foF2 and ITEC observed before six days from the main shock. Fig. 5 shows the variation of ionospheric foF2 parameter and 
ITEC. Fig. 6 to 7 shows the wavelet analysis variation pattern for foF2 parameter and ITEC. Its was noticed that these parameters shows highly abnormal behavior at February 07, 2008 seven day before the main shock and it was also noticed that the signal shows non-stationary behavior during this time.

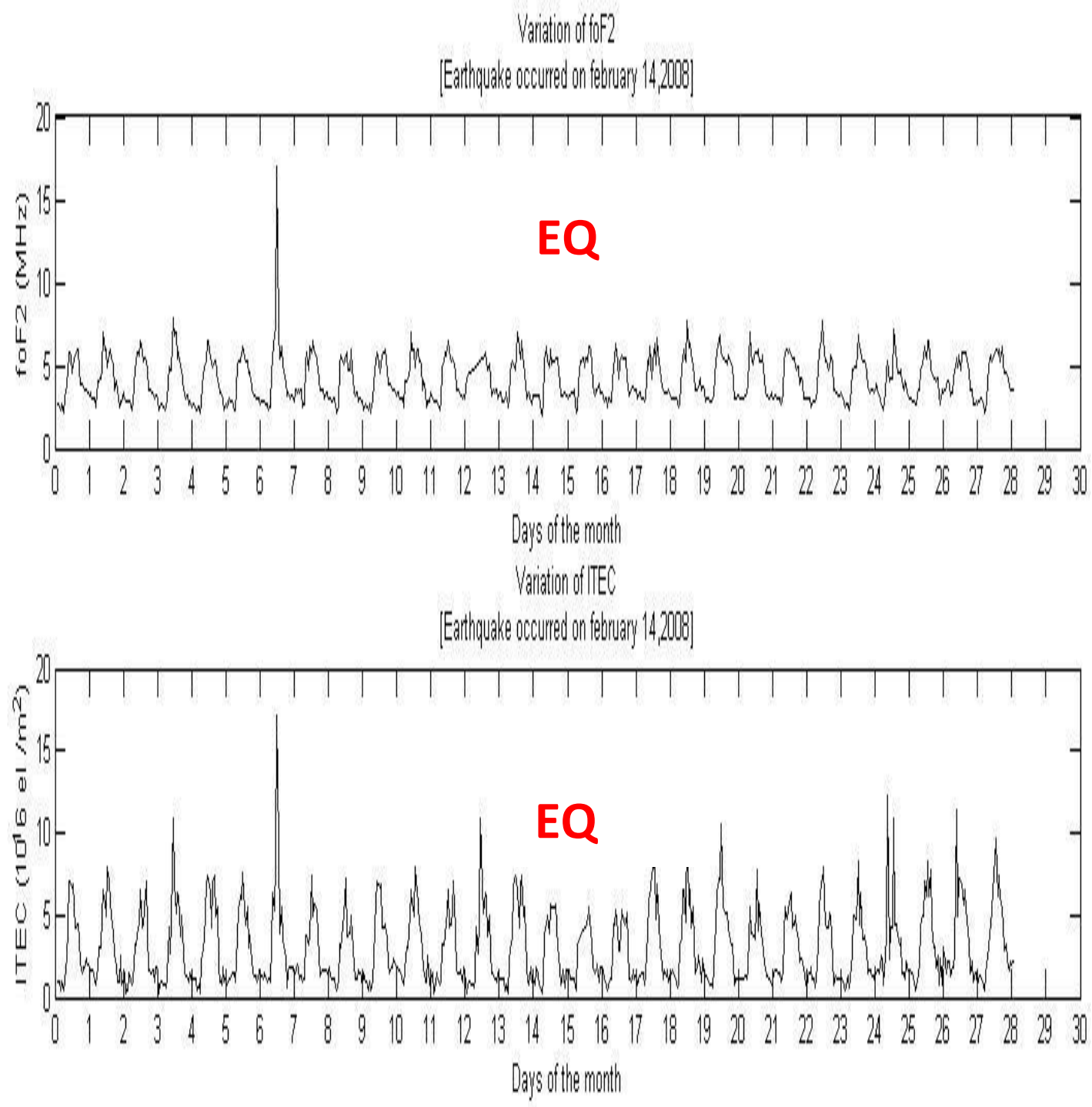

Fig. (5) Variation of ionospheric foF2 parameter and ionospheric Total Electron Content (ITEC) using Southern Greece Earthquake occurred on February 14, 2008 
Signal and Approximation a t level 1

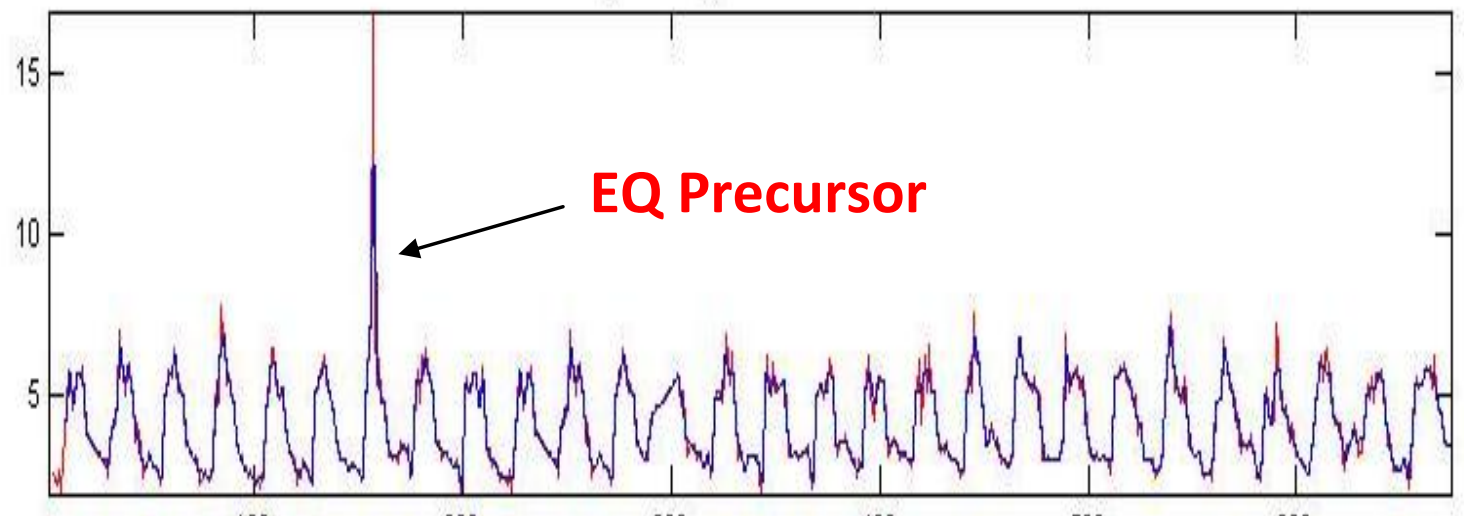

100

300

400

500

600

Detail at level 1

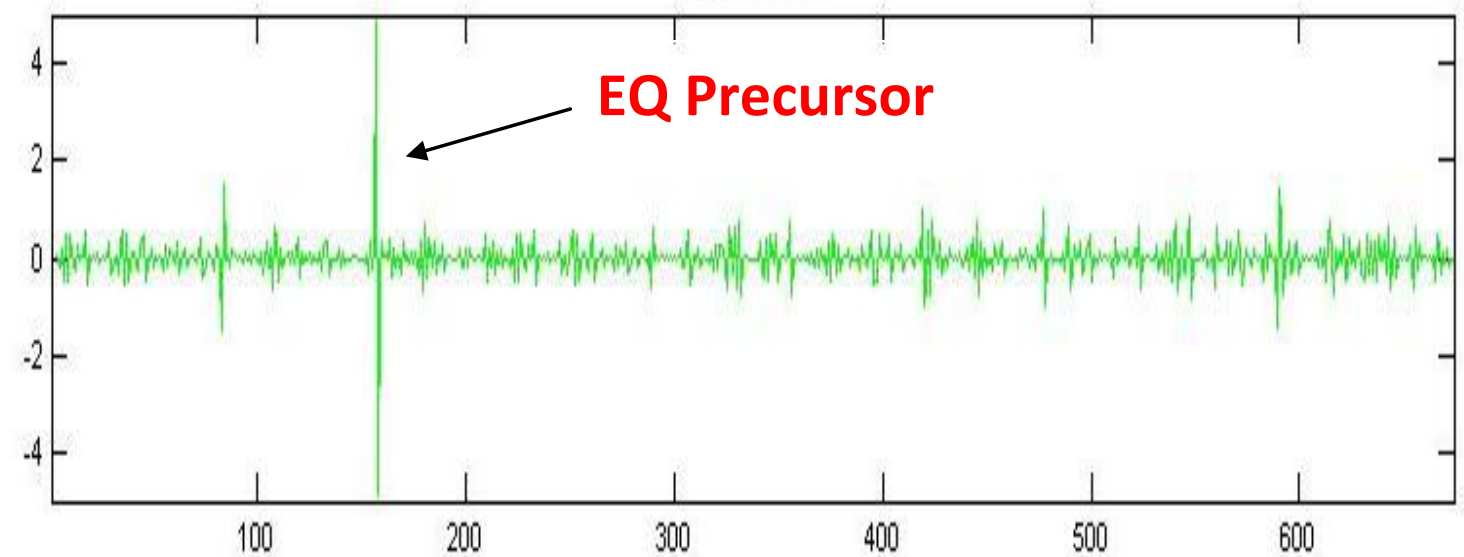

Detalls Coesficierts

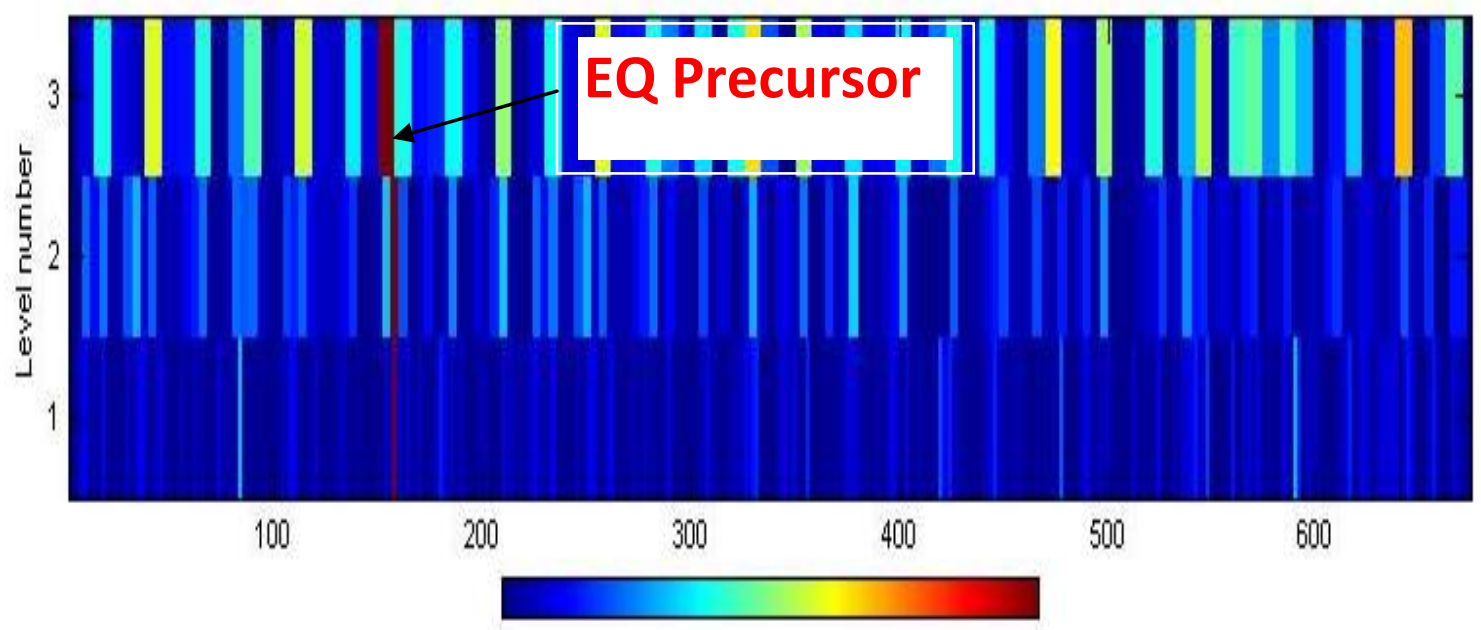

Scale of colors from MAlN to MaX

Fig. 6 (a) Discrete Wavelet Transform of Ionospheric foF2 parameter during Southern Greece Earthquake occurred on February 14, 2008 
Signal and Approximation a tlevel 1

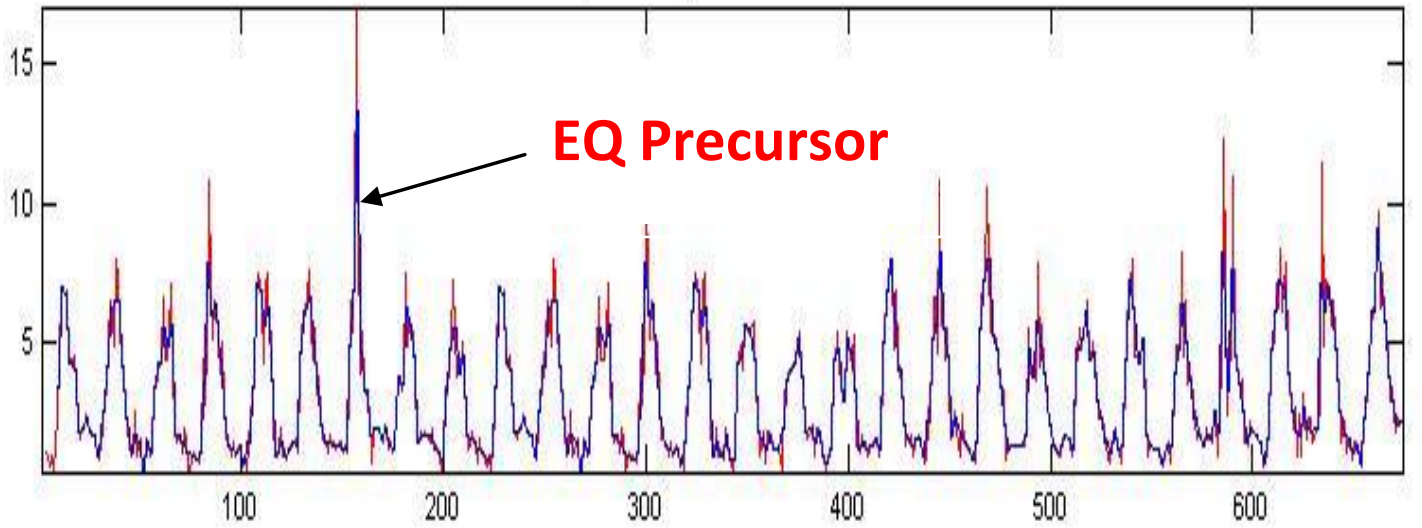

Detali at level 1

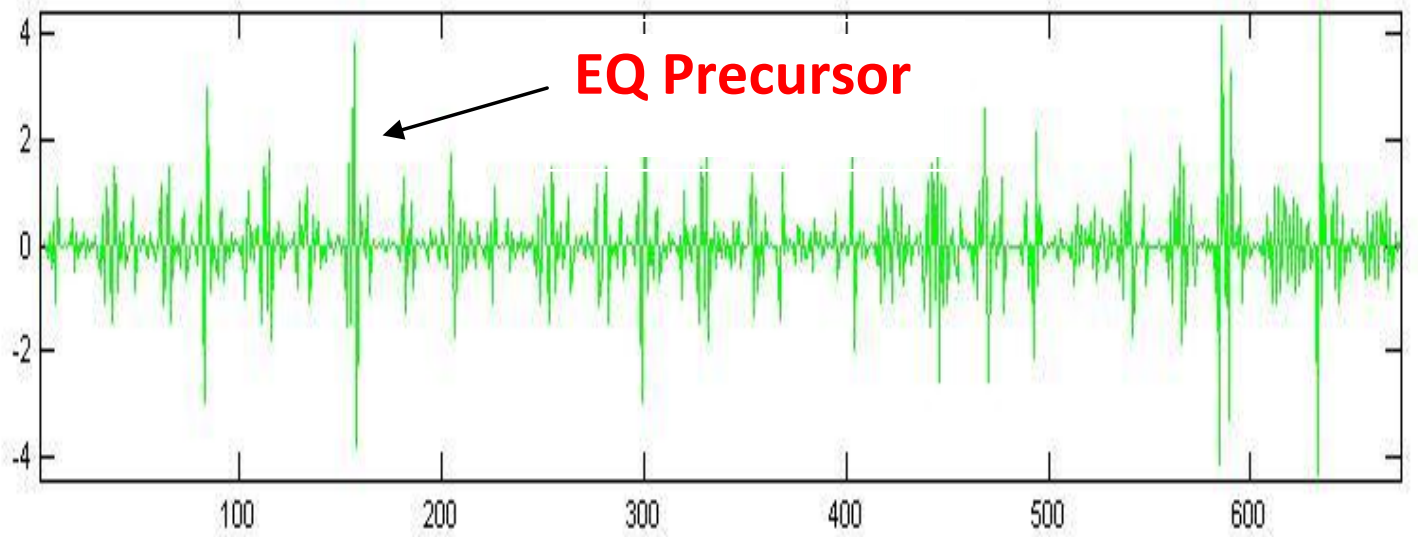

Details Coefficierts

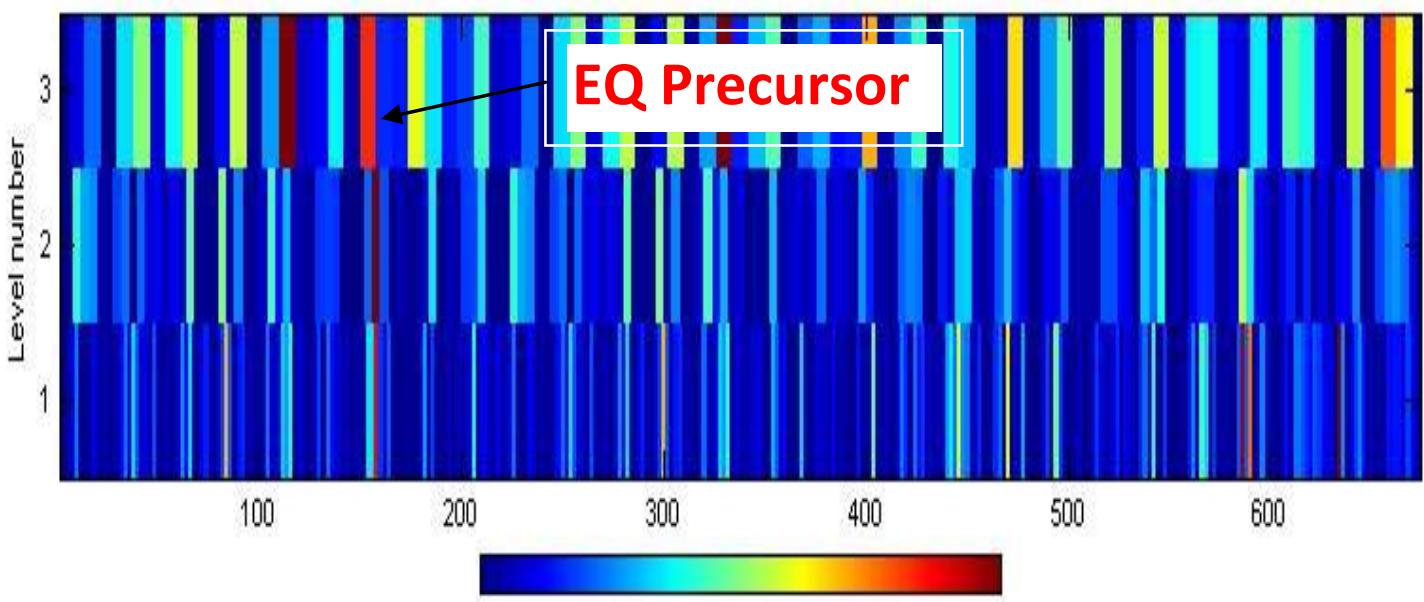

Scale of colors from MNN to MAX

Fig. 6 (a) Discrete Wavelet Transform of Ionospheric total electron content (ITEC) parameter during Southern Greece Earthquake occurred on February 14, 2008 


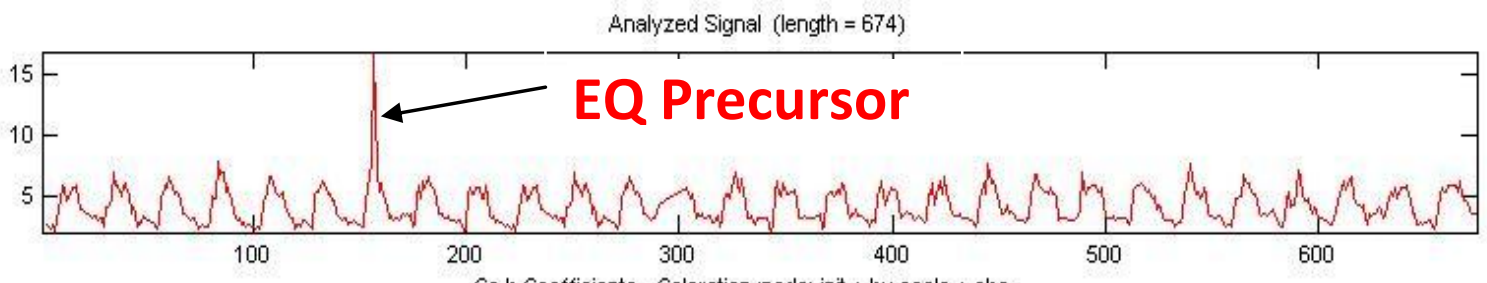

Ca b Coefficients - Coloration mode: init + by scale + abs

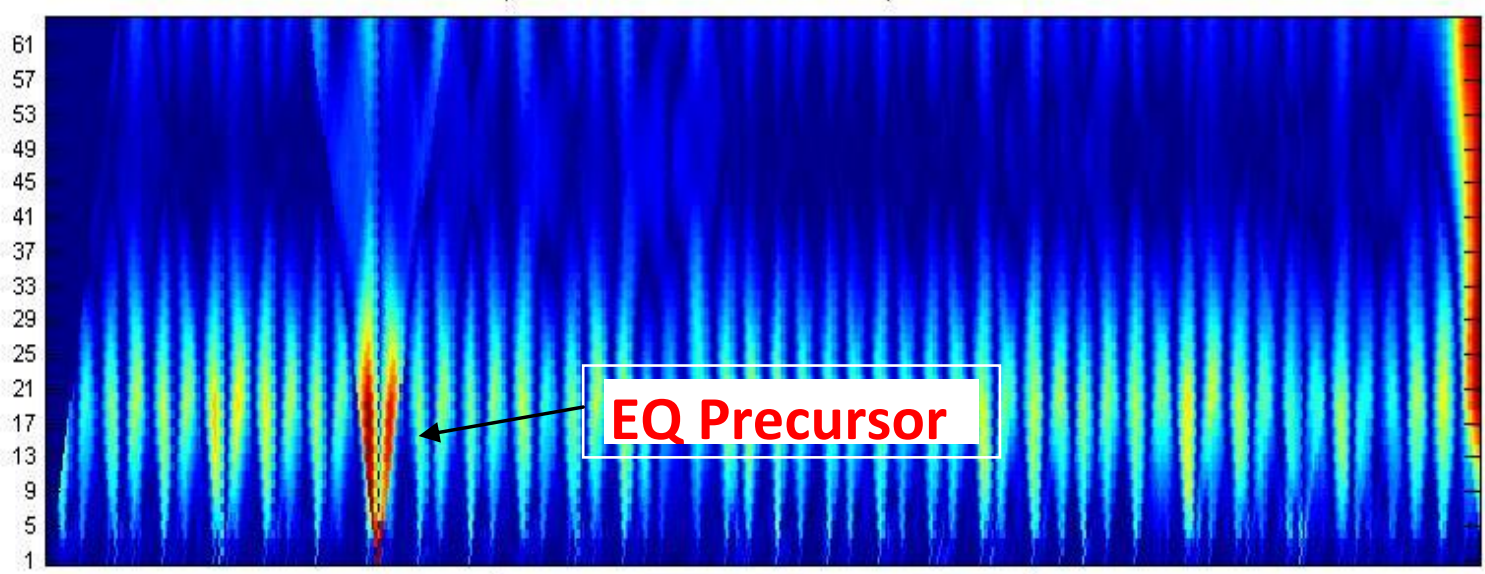

Scale of colors from MIN to MAX

Fig. 7 (a) Continuous wavelet transform of Ionospheric foF2 parameter during Southern Greece Earthquake occurred on February 14, 2008
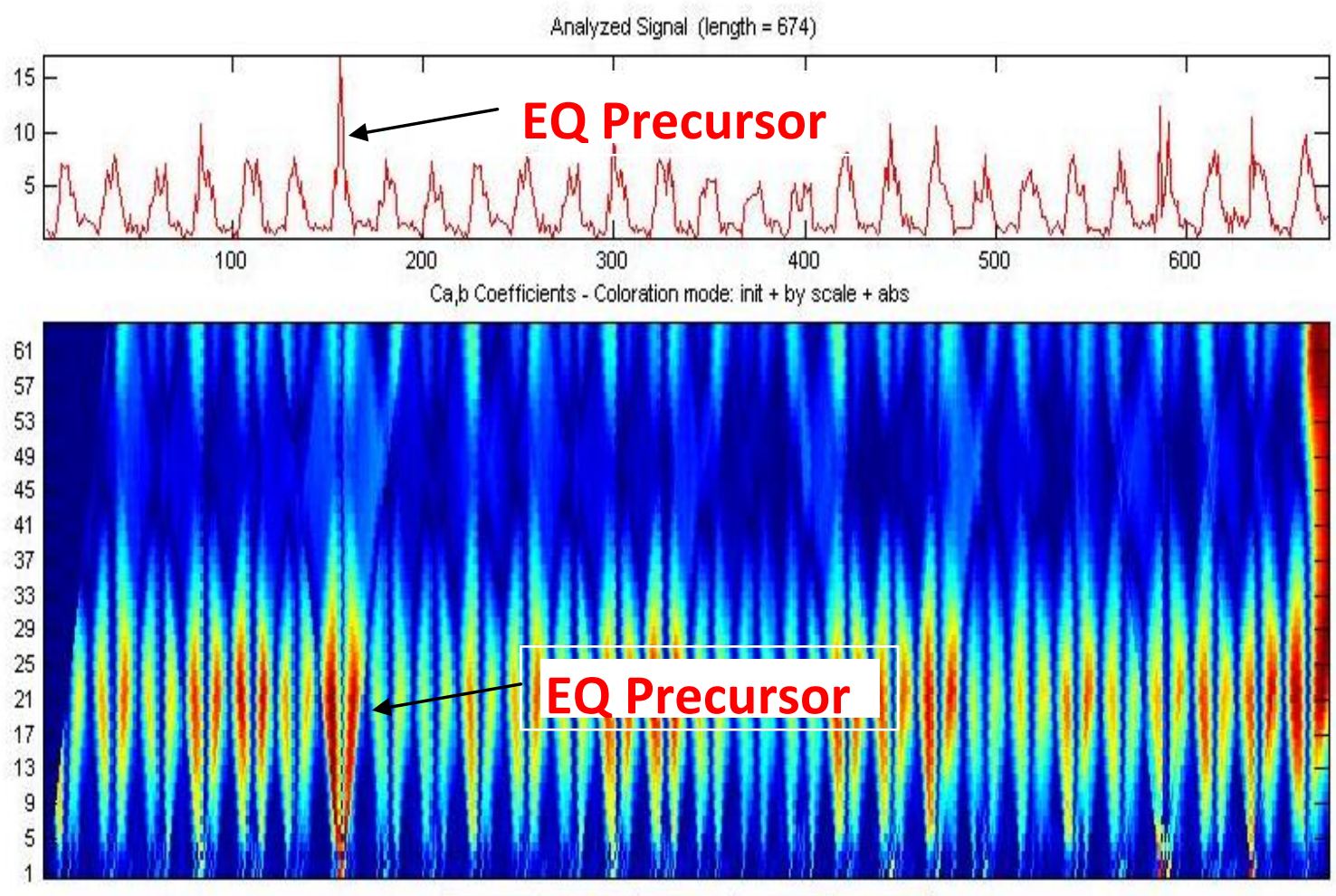

Scale of colors from MinN to MAX

Fig. 7 (b) Continuous wavelet transform of Ionospheric total electron content (ITEC) parameter during Southern Greece Earthquake occurred on February 14, 2008 


\section{Greece-Peloponnese Earthquake Occurred On June 08, 2008:}

A strong earthquake measuring 6.4 magnitudes on the Richter scale took place on June 08, 2008, at 13:25 UT in Peloponnese Greece $\left(38.029^{\circ} \mathrm{N}, 21.464^{\circ} \mathrm{E}\right)$. Its depth was $10.5 \mathrm{~km}$.Variation of ionospheric foF2 and ITEC parameters are shown in Fig. 8. The result of analysis was illustrated in Fig. 9 for discrete wavelet transform and Fig. 10 for continuous wavelet transform. Its shows highly abnormal behavior at June 01, 2008 seven day before the earthquake and it is also noticed that the signal shows non-stationary behavior during this time.
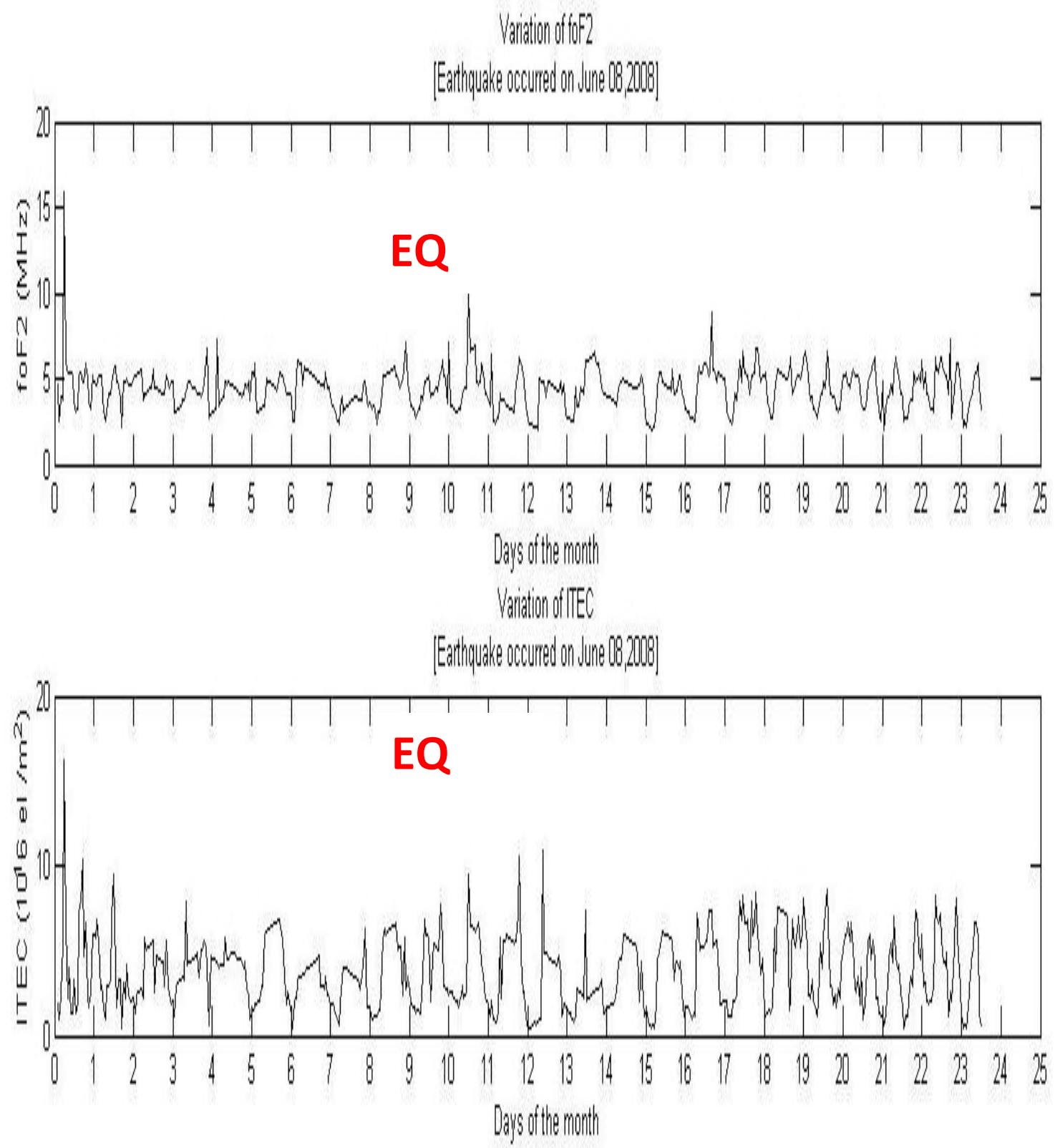

Fig. 8 Variation of ionospheric foF2 parameter and ionospheric Total Electron Content (ITEC) during Peloponnese Greece Earthquake occurred on June 08, 2008 
Signal and Approximation at level 1

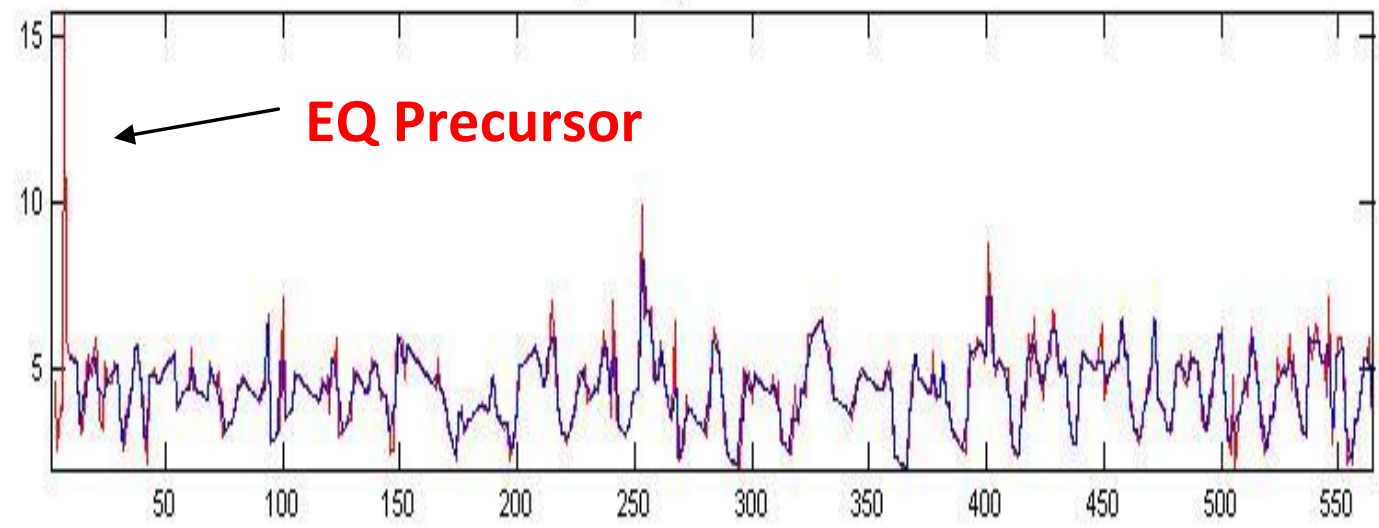

Detail at level 1

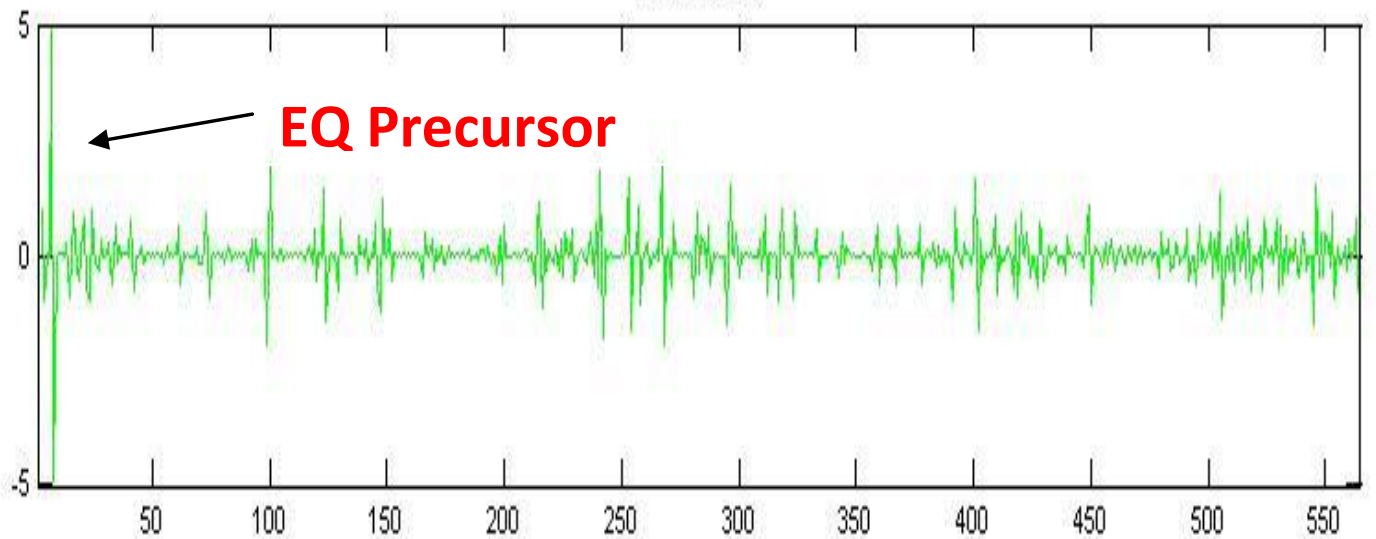

Details Coefficients

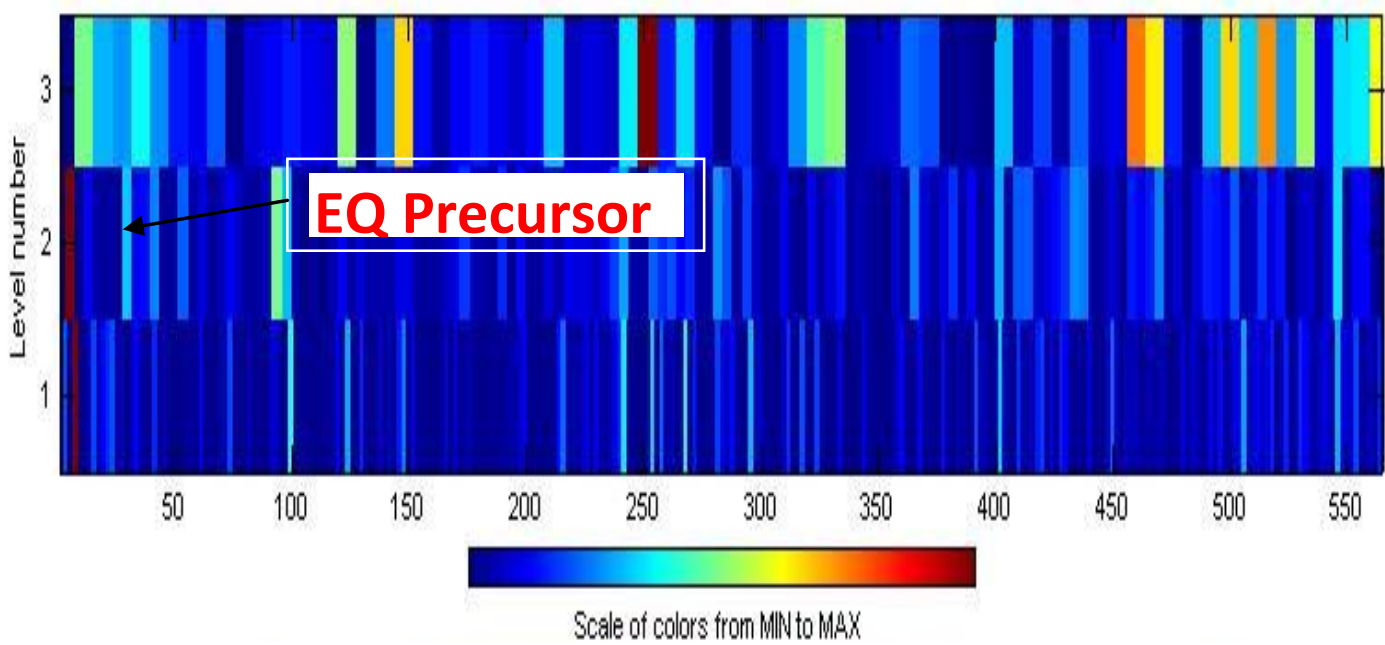

Fig. 9 (a) Discrete Wavelet Transform of Ionospheric foF2 parameter during Peloponnese Greece Earthquake occurred on June 08, 2008 
Signal and Approximation at level 1

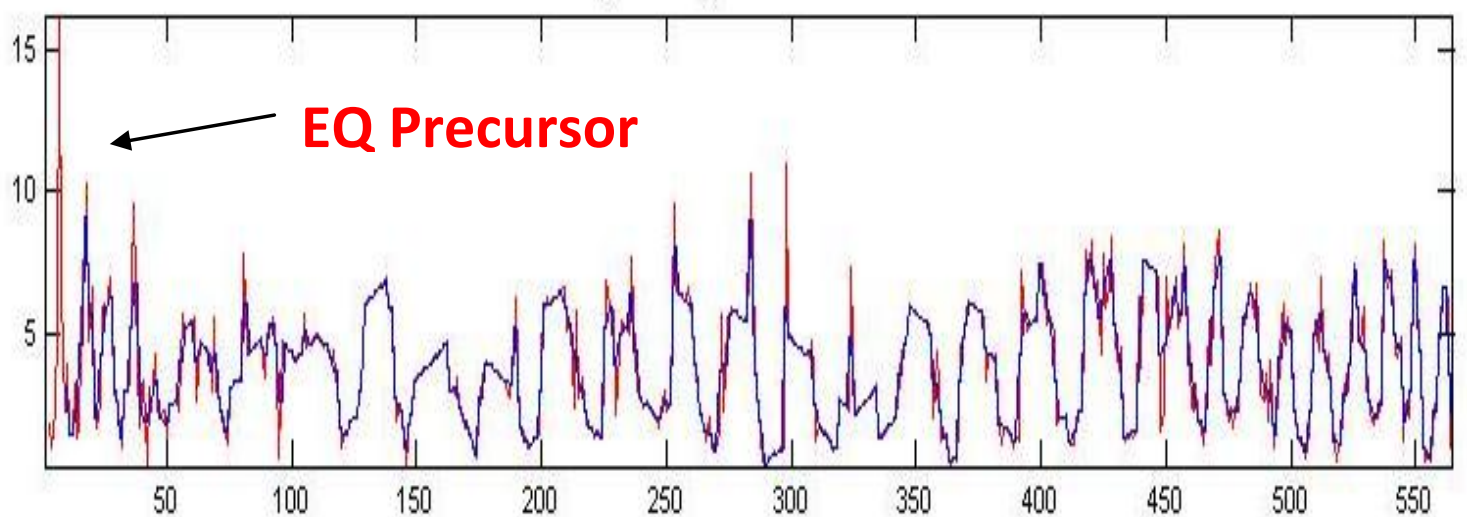

Detail at level 1

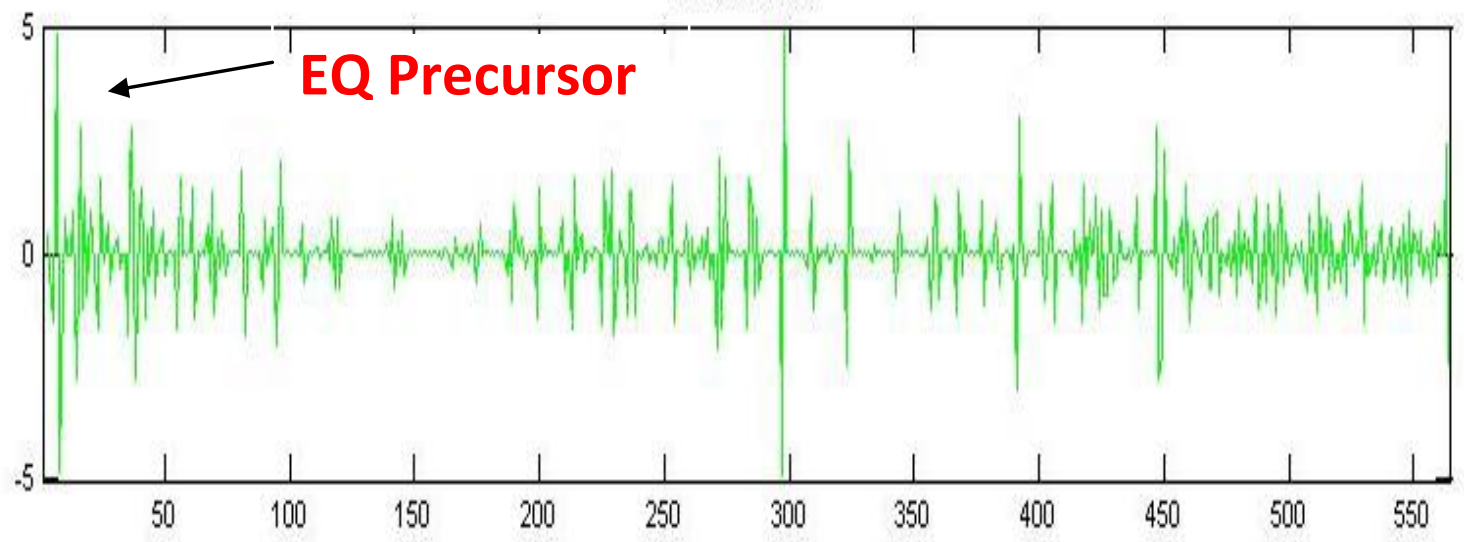

Details Coefficients

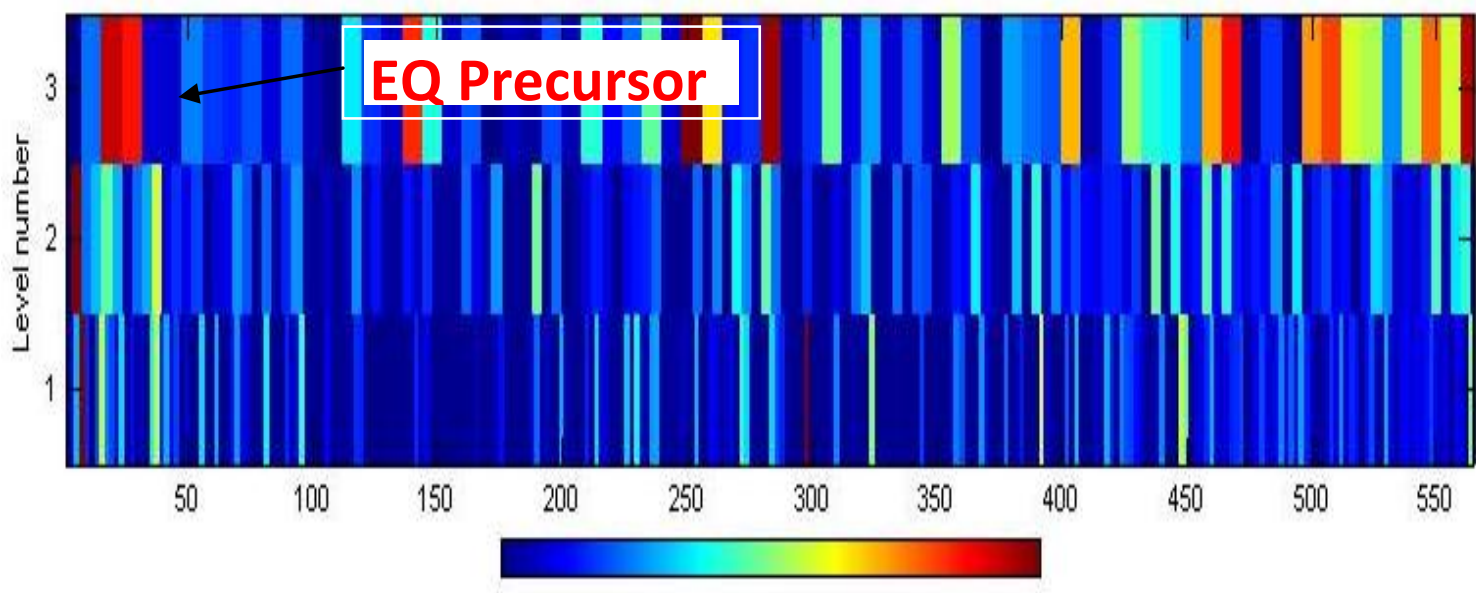

Scale of colors from MNN to MAX

Fig. 9 (b) Discrete Wavelet Transform of ionospheric Total Electron Content (ITEC) during Peloponnese Greece Earthquake occurred on June 08, 2008 

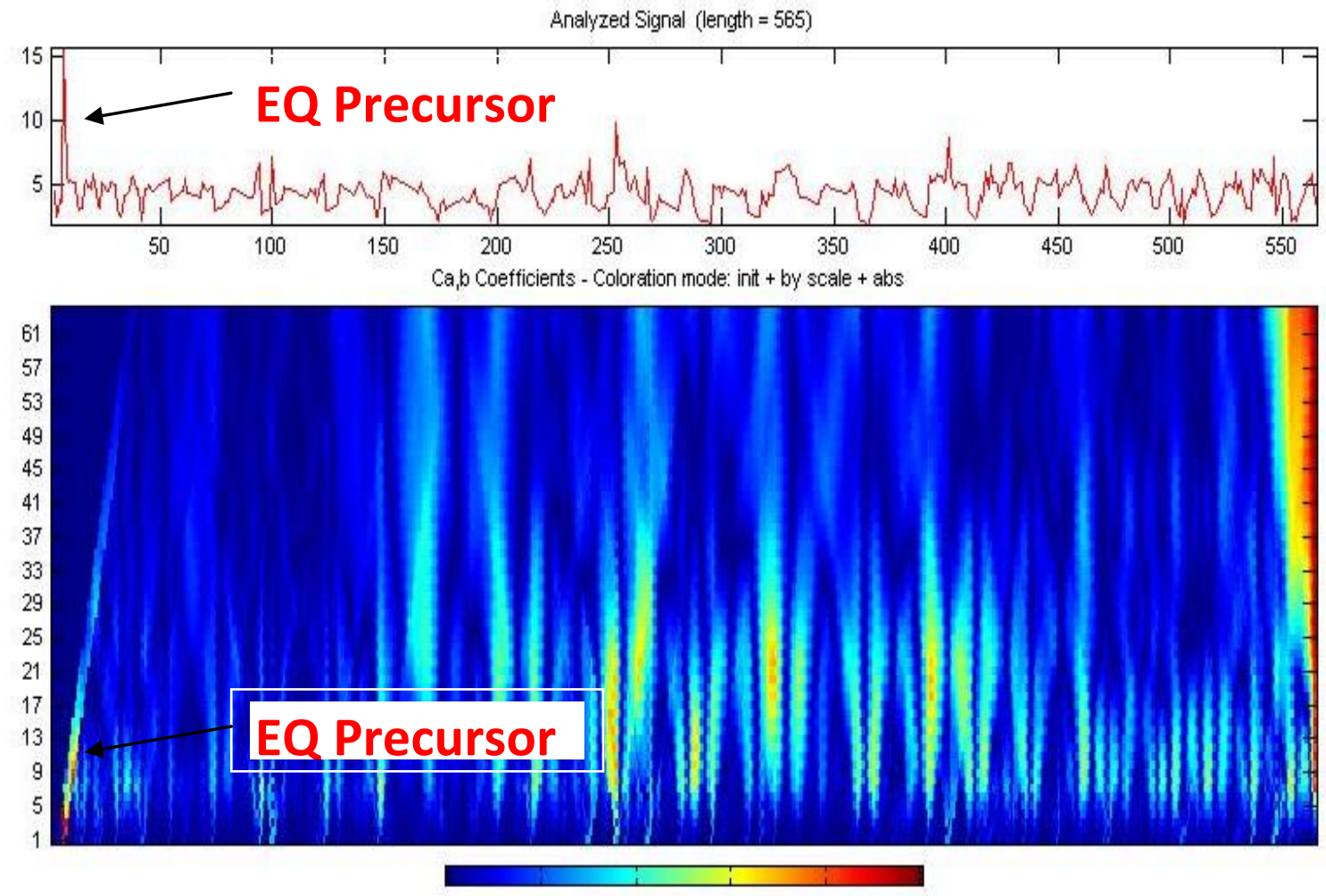

Scale of colors from MINN to MAX

Fig. 10 (a) Continuous wavelet transform of Ionospheric foF2 parameter during Peloponnese Greece Earthquake occurred on June 08, 2008
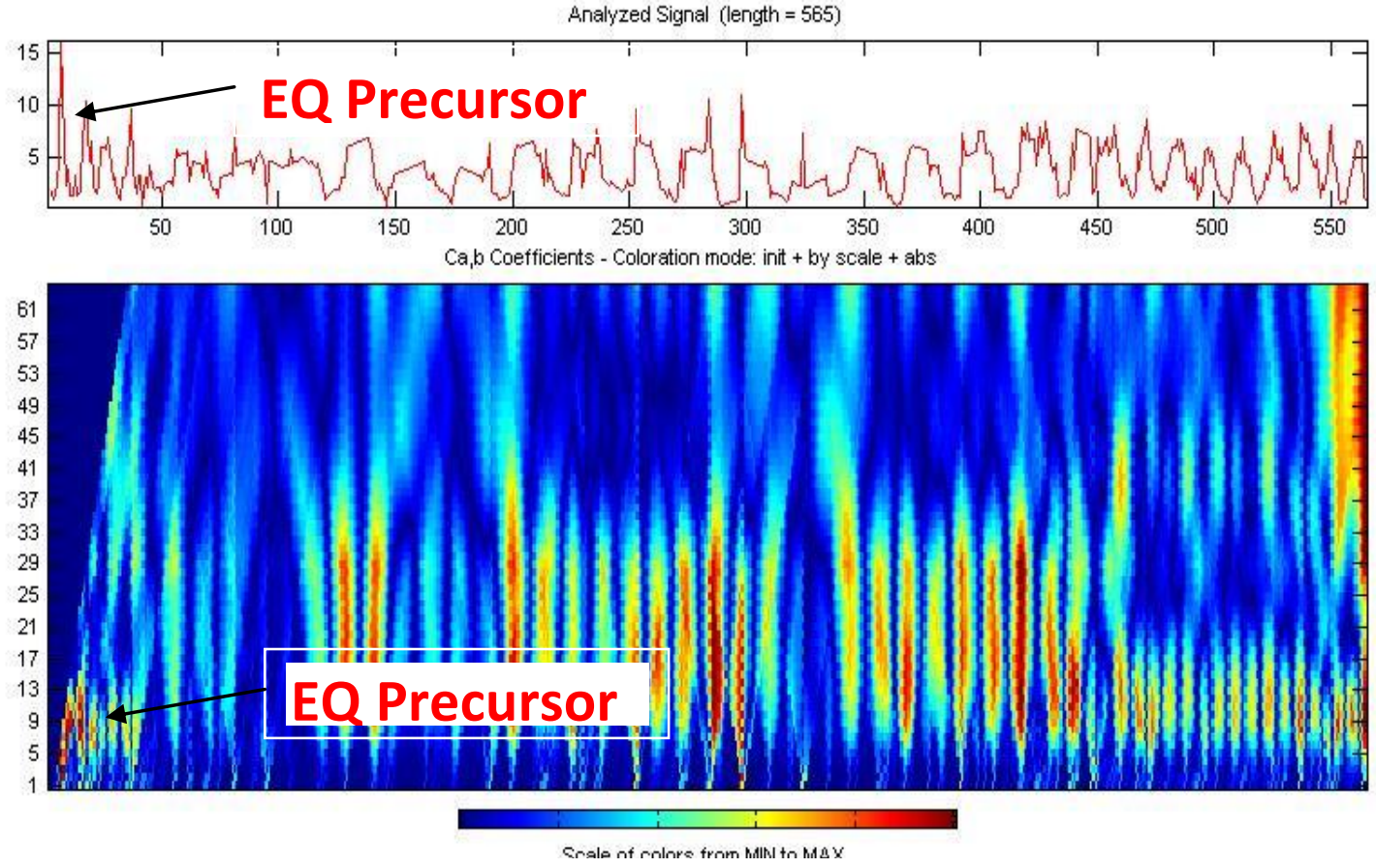

Fig. 10 (b) Continuous wavelet transform of Ionospheric foF2 parameter during Peloponnese Greece Earthquake occurred on June 08, 2008 


\section{Discussion And Conclusions:}

In this work the features of seismo-ionospheric variations registered by ground - based techniques that appear before the earthquakes have been demonstrated. These variations include the variation in ionospheric foF2 and ITEC parameters. The ionosonde measurements show ionospheric perturbations after the occurrence of the main shock. Also, these variations were independent of geomagnetic storm as the Dst values were quiet or moderate during these days with no geomagnetic storm during this period. The ITEC and foF2 measurements confirm that the ionosphetere was disturbed some days before the earthquake at greater distance from the epicenter. The ionospheric variations have been observed during the earthquakes using different parameters ITEC and foF2 obtained from different techniques. The area of the variations of ionospheric parameters is of the same order of magnitude as size of the earthquake preparation zone on the ground surface [19]. Thus the present detection of anomalies during the earthquakes leads us to believe that coordinate measurements of ground based observations of ionospheric parameters can help in reliable detection of ionospheric precursors with more observations obtained from several stations.

The ionospheric perturbations observed in the F-layer are the most important ones as it is the most dense and most dynamical layer of the ionosphere. Pulinets used the data of Alouette-1 and Intercoms -19 satellites to study the variation in the critical frequency of F2 layer during earthquake [2]. They reported the formation of large - scale irregularities of electron concentrations in F2 region of the ionosphere during the preparatory phase of destructive earthquakes. The ground based ionospheric measurements using ionosonde shows strong anomalous disturbances in the ionosphere near the earthquake epicenter. The anomaly in the foF 2 data was found before three to nine days from the main shock. Chen et al. analyzed the foF2 data associated with $\mathrm{M}>5$ earthquakes and found the chance of observing the precursor within five days prior to the earthquakes [23]. The ionospheric precursors of earthquake and reported observed precursors some days prior to the main shock [1], [3]. The main cause of above observed ionospheric anomalies might be due to the upward propagation of seismogenic electric fields, which are initially generated near the surface of the earth during the earthquake preparation period [24]. This dynamical process modified the height distribution of electric conductivity and induced the additional electromotive force in the lower ionosphere by the closed global electric circuit in the earth ionosphere system. This modification leads to perturbation in the F- region ionosphere; so as to change in ITEC and foF2 values. This anomalous behavior may be used as earthquake precursors.

\section{References:}

[1] S.A. Pulinets, and K.A. Boyarchuk, Ionospheric Precursors of Earthquakes (Springer, Berlin, Germany, 2004)

[2] S.A. Pulinets, A.D. Legen_ka, T.I. Zelenova, Local-time dependence of seismo-ionospheric variations at the F-layer maximum. Geomagn.Aeronom, 38, 1998, 400-402.

[3] J.Y. Liu, Y.I. Chen, S.A. Pulinets, Y.B. Tsai, and Y.J. Chuo, Seismoionospheric signatures prior to MP 6.0 Taiwan earthquakes. Geophys, Res. Lett. 27, 2000, 3113-3117.

[4] R.D. Hunsucker, Radio Techniques for Probing the Terrestrial Ionosphere, (Thomson Press India Ltd., 1991)

[5] Y.I. Chen, J.Y. Liu, Y.B. Tsai, C.S. Chen, Statistical tests for preearthquakeionospheric anomaly, Terr., Atm. Ocean Sci. 15, 2004, 936- 943.

[6] V.H. Rios, V. P. Kim, V. V. and Hegai, Abnormal perturbations in the F2 region ionosphere observed prior to the great San Juan earthquake of 23 November 1977, Adv. Space. Res., 33(3), 2004, 323-327, doi:10.1016/S0273-1177(03)00480-0.

[7] R.S. Dabas, Rupesh, M. Das, K.M. Sharma, and K.G. Pillai, Ionospheric precursors observed over low latitudes during some of the recent major earthquakes, J. Atmos. Sol.-Terr. Phy., 69(15), 2007, 1813-1824.

[8] A.Kh. Depueva, A.V. Mikhailove, M. Devi, and A.K. Barbara, Spatial and time variations in critical frequencies of the ionopsheric F region above the zone of equatorial earthquake preparation, Geomagn.Aeron., 47(1), 2007, 129-133.

[9] E.V. Liperovskaya, P.F. Biagi, C.V. Meister, and M.V. Rodkin, foF2 seismo-ionospheric effect analysis: actual data and numerical simulations, Nat. Hazards Earth Syst. Sci., 8, 2008, 1387-1393, doi:10.5194/nhess-8-1387-2008.

[10] E.V. Liperovskaya, V.V., Bogdanov, P.F. Biagi, C.V. Meister, V.A. Liperovsky, and M.V. Rodkin, Day-time variations of foF2 connected to strong earthquakes, Nat. Hazards Earth Syst.Sci., 9, 53-59, 2009, doi:10.5194/nhess-9-53-2009.

[11] K. Sharma, R.M. Das, R.S. Dabas, K.G.M. Pillai, S.C. Garg, and A.K. Mishra, Ionospheric precursors observed at low latitudes around the time of Koyna earthquake, Adv. Space Res., 42(7), 1238-1245, 2008, doi:10.1016/j.asr.2007.06.026.

[12] Tsolis, G. S. and Xenos, T. D.: A qualitative study of the seismoionospheric precursors prior to the 6 April 2009 earthquake in L'Aquila, Italy, Nat. Hazards Earth Syst. Sci., 10, 133-137, 2010, doi:10.5194/nhess-10-133-2010.

[13] T. Xu, Y.L. Hu, J. Wu, and Z.S. Wu, Anomalous enhancement of electric field derived from ionosonde data before the greatWenchuan earthquake, Adv. Space Res., 47(6), 2011, 1001-1005,doi:10.1016/j.asr.2010.11.006.

[14] C.K. Chui, An introduction to wavelets (Academic Press, San Diego,1992).

[15] I. Daubechies, Ten lectures on wavelets (SIAM, Philadelphia,1992).

[16] A. Soneand S. Yamamoto, Wavelet analysis: Its origination, development, and applications (in Japanese).

[17] S. Mallat, Zero-crossings of a wavelet transform, IEEE Transactions on Information Theory, 37, 1991, 1019-1033.

[18] B. Jawerth, W. Sweldens, An overview of wavelet based multiresolution analysis, SIAM Review 36 (3), ,1994, $377-412$.

[19] I.R. Dobrovolsky, S.I. Zubko, and V.I. Mayachkin, Estimation of the size of earthquake preparation zones, Pure Appl. Geophys., 117(5), 1979, 1025-1044.

[20] S.A. Pulinets, K. A., Boyarchun, V.V. Hegai, V. P. Kim, and A.M. Lomonosov, Quasielectrostatic model of atmospherethermosphere-ionosphere coupling, Adv. Space Res., 26(3), 2000, 1209-1281, doi:10.1016/S0273-1177(99) 01223-5. 
[21] S.A. Pulinets, K.A. Boyarchuk, A.M. Lomonosov, V.V. Khegai, J.Y. Liu, Ionospheric precursors to earthquakes: a preliminary analysis of the foF2 critical frequencies at Chung-Li ground-based station for vertical sounding of the ionosphere (Taiwan island), Geomagn. Aeronom. 42, 2002, 508-513.

[22] W.D. Gonzalez, J.A. Joselyn, Y. Kamide, H.W. Kroehl, G. Rostoker, B.T. Tsurutani, and V.M. Vasyliunas, What is a geomagnetic storm? J. Geophys. Res., 99,1994, 5771-5792.

[23] Y.I. Chen, J.Y. Chuo, J.Y. Liu, and S.A. Pulinets, Statistical study of ionospheric precursors of strong earthquakes at Taiwan area, XXVI URSI General Assembly, Toronto, 13-21 Aug. 1999, Abs., 745p.

[24] M. Hayakawa, (Ed.), Atmospheric and Ionospheric Electromagnetic Phenomena with Earthquakes (TERRAPUB, Tokyo, 1999). 